OPEN ACCESS

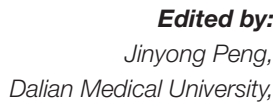

China

Reviewed by:

Xufeng Tao,

Dalian University of Technology

(DUT), China

Binan Lu,

Minzu University of China, China

Dapeng Chen,

Dalian Medical University, China

${ }^{*}$ Correspondence:

Chuantao Tu

tu.chuantao@zs-hospital.sh.cn

Specialty section: This article was submitted to Gastrointestinal and Hepatic Pharmacology, a section of the journal

Frontiers in Pharmacology

Received: 09 June 2019 Accepted: 26 August 2019 Published: 20 September 2019

Citation:

Li X, Yao Q, Huang J, Jin Q, Xu B,

Chen F and Tu C (2019) Morin

Hydrate Inhibits TREM-1/TLR4Mediated Inflammatory Response in Macrophages and Protects Against Carbon Tetrachloride-Induced Acute Liver Injury in Mice.

Front. Pharmacol. 10:1089. doi: 10.3389/fphar.2019.01089

\section{Morin Hydrate Inhibits TREM-1/ TLR4-Mediated Inflammatory Response in Macrophages and Protects Against Carbon Tetrachloride-Induced Acute Liver Injury in Mice}

\author{
Xi Li ${ }^{1}$, Qunyan Yao ${ }^{2}$, Jiying Huang ${ }^{3}$, Qianwen Jin ${ }^{2}$, Beili X ${ }^{2}$, Fangyuan Chen ${ }^{2}$ and \\ Chuantao $\mathrm{Tu}^{2 *}$
}

\begin{abstract}
${ }^{1}$ Department of Geriatrics, Zhongshan Hospital, Fudan University, Shanghai, China, ${ }^{2}$ Department of Gastroenterology and Hepatology, Zhongshan Hospital, Fudan University, Shanghai, China, ${ }^{3}$ Department of Gastroenterology and Hepatology, Zhongshan Hospital Qingpu Branch, Fudan University, Shanghai, China
\end{abstract}

This study aims to investigate the protective effects of morin hydrate $(\mathrm{MH})$ against acute liver injury induced by carbon tetrachloride $\left(\mathrm{CCl}_{4}\right)$ in mice and to elucidate the possible molecular mechanism of action. Mice were pretreated with $\mathrm{MH}(50 \mathrm{mg} / \mathrm{kg}$ body weight) or vehicle by oral gavage once daily for 5 days, followed by intraperitoneal injection of a single dose of $\mathrm{CCl}_{4}(1 \mathrm{ml} / \mathrm{kg}$ in olive oil). Mice were sacrificed $24 \mathrm{~h}$ later; the blood and liver samples were harvested for analysis. We also used the model of lipopolysaccharide (LPS)-stimulated RAW264.7 macrophages in vitro and examined the effects of $\mathrm{MH}$ and its mechanism of action on the inflammatory response. Our results revealed that $\mathrm{MH}$ remarkably attenuated liver histopathological alterations, serum transaminases, hepatocytes death, and inflammatory response induced by $\mathrm{CCl}_{4}$. Importantly, $\mathrm{MH}$ reduced expression of the triggering receptor expressed on myeloid cells-1 (TREM-1) and tolllike receptor 4 (TLR4) both in vivo and in vitro experiments. This inhibitory effect $\mathrm{MH}$ on expression of the TREM-1 and TLR4 in cell culture was further heightened after TREM-1 knockdown with small interfering RNA (siRNA). Moreover, MH dramatically suppressed the inhibitor of kappa $B \alpha(1 \kappa B \alpha)$ degradation and subsequent nuclear factor-kappa B (NFкB) p65 translocation into the nucleus and NF-кB-mediated cytokines, such as tumor necrosis factor $\alpha$ (TNF- $\alpha$ ), interleukin (IL)-1 $\beta$, and IL-6. Additionally, MH also ameliorated $\mathrm{CCl}_{4}$-induced oxidative stress by enhancing the nuclear factor erythroid 2-related factor 2 (Nrf2) and heme oxygenase-1 (HO-1) expression in the injured livers. Taken together, $\mathrm{MH}$ has hepatoprotective activity, and this effect may be elicited by attenuating macrophagemediated inflammatory responses via inhibition TREM-1/TLR4/NF-kB signaling and by regulating hepatic oxidative stress via enhancement $\mathrm{Nrf2} / \mathrm{HO}-1$ antioxidant pathway.

Keywords: liver injury, morin hydrate, inflammatory response, TREM-1, TLR4, NF-KB, oxidative stress 


\section{INTRODUCTION}

Acute liver injury is a common pathway to many liver diseases and remains a serious health problem worldwide associated with significant morbidity and mortality (Malhi and Gores, 2008; Bernal et al., 2010). It is worth noticing that if acute liver injury persists, it may lead to chronic liver inflammation and fibrosis, eventually progressing to cirrhosis and hepatocellular carcinoma (Malhi and Gores, 2008; Reilkoff et al., 2011; Dong et al., 2015). However, there is no specific treatment for acute liver injury. Hence, it is urgently needed to develop novel therapeutic methods to prevent acute liver injury and inflammation.

Hepatic inflammation is a complex process that is a response to a wide range of stimuli that induce oxidative stress and injury to hepatocytes (Kubes and Mehal, 2012; Zhang et al., 2015; Li et al., 2016b; Hassan et al., 2017; Krenkel and Tacke, 2017). Previous data have demonstrated that some endogenous and exogenous antioxidants may protect against oxidative-induced liver injury and inflammation (Lu et al., 2012; He et al., 2016; Lin et al., 2018; Mortezaee and Khanlarkhani, 2018). Actually, it has been suggested that, in most cases, hepatocellular injury is not due to the damaging agent itself but to the activation of the immune cells such as Kupffer cells (He et al., 2016; Krenkel and Tacke, 2017; Lin et al., 2018). It is well known that Kupffer cells are liver-resident tissue macrophages and the principal mediators for native and adaptive inflammatory responses (Antoniades et al., 2008; Krenkel and Tacke, 2017). Moreover, several lines of evidence have indicated that inflammatory responses mediated by cytokines and chemokines play an important role in cell death and liver injury (Sims et al., 2010; Kubes and Mehal, 2012; Lu et al., 2012; Krenkel and Tacke, 2017).

Triggering receptor expressed on myeloid cells-1 (TREM-1), a member of TREM family, is a kind of immunoglobulin (Ig) superfamily activation receptor related to innate inflammatory response (Tammaro et al., 2017). Of note, TREM-1 is an activating receptor expressed on neutrophils and monocyte/ macrophages (Ornatowska et al., 2007; Tammaro et al., 2017). Upon activation, TREM-1 can trigger and amplify inflammatory responses, especially through interaction with toll-like receptor (TLR) signaling in macrophages (Klesney-Tait et al., 2006; Ornatowska et al., 2007; Tammaro et al., 2017). Previous studies have further demonstrated TREM-1 is a master regulator of Kupffer cell activation, which escalates acute and chronic inflammatory responses in liver diseases (Nguyen-Lefebvre et al., 2018; Rao et al., 2019). A recent study found that knockdown of TREM- 1 can ameliorate the inflammatory response and lipid accumulation of nonalcoholic fatty liver disease (NAFLD) mice inactivation of TREM-1/nuclear factor-kappa B (NF-кB) and TREM-1/PI3K/AKT axis (Rao et al., 2019). In addition, previous studies have revealed that TLR-mediated signals are involved in almost all liver diseases (Seki et al., 2007; Mencin et al., 2009; Li et al., 2016a), and TLR4/NF- $\mathrm{kB}$ signaling is of particular importance for liver injury (Seki et al., 2007; Li et al., 2016a). NF- $\mathrm{kB}$ is a cardinal regulator of inflammatory response, controlling the expression of genes that encode cytokines such as tumor necrosis factor $\alpha$ (TNF- $\alpha$ ), interleukin (IL)- $1 \beta$, and IL-6 (Seki et al., 2007; Mencin et al., 2009; Li et al., 2016a). Therefore, these data indicate that TREM-1/TLR4-mediated inflammatory response plays a pivotal part in liver injury and inflammation and may serve as a promising therapeutic target for preventing acute liver injury.

Morin hydrate (MH; 2',3,4',5,7-pentahydroxyflavone; Figure 1A), a member of the flavonoids, is a yellow-colored compound that can be separated from members of the Moraceae plants family (Lee et al., 2016; Naowaboot et al., 2016); it is also found in many herbs, red wine, and fruits like almond, guava, sweet chestnut, and onion (Caselli et al., 2016; Lee et al., 2016; Naowaboot et al., 2016). $\mathrm{MH}$ has been reported to possess antioxidant, neuroprotective, anti-inflammatory, antihypertensive, and anticancer properties (Dong et al., 2015; Caselli et al., 2016; Lee et al., 2016; Naowaboot et al., 2016). In particular, MH has also shown to inhibit liver injury, inflammation, and fibrosis in several different animal models by its antioxidant and anti-inflammatory effects (Rizvi et al., 2015; Gu et al., 2017; Perumal et al., 2017; Tian et al., 2017). However, the exact molecular mechanism underlying the hepatoprotective effect of $\mathrm{MH}$ is still partially understood. Therefore, the aims of this study were to investigate the protective effects of $\mathrm{MH}$ against acute liver injury in mice and to elucidate its underlying mechanisms.

\section{MATERIALS AND METHODS}

\section{Reagents and Antibodies}

$\mathrm{MH}$, lipopolysaccharide (LPS), dimethyl sulfoxide (DMSO), and 3-(4,5-dimethylthiazol-2-yl)-2,5-diphenyltetrazolium bromide (MTT) were purchased from Sigma-Aldrich (St. Louis, MO, USA). Carbon tetrachloride $\left(\mathrm{CCl}_{4}\right)$ was purchased from Shanghai Macklin Chemical Co., Ltd. (Shanghai, China). TNF- $\alpha$ and IL-1 $\beta$ enzyme-linked immunosorbent assay (ELISA) kits were from R\&D Systems (Minneapolis, MN, USA). Lipid peroxidation malondialdehyde (MDA) assay kit, total glutathione assay kit, and total superoxide dismutase (SOD) assay kit were from Beyotime Institute Biotechnology (Shanghai, China). TRIzol reagent is from Life Technologies (Grand Island, NY, USA). Mouse anti-NFkB p65 polyclonal antibody and rabbit anti-IкB monoclonal antibody were from Cell Signaling Technology (Boston, MA, USA); rabbit anti-TLR4 monoclonal antibody was from Epitomics, Inc. (Burlingame, CA); rabbit anti-Nrf2 monoclonal antibody, rabbit anti-TREM-1 polyclonal antibody, rat anti-F4/80 monoclonal antibody, rabbit anti-HO-1 polyclonal antibody, rabbit antiGAPDH monoclonal antibody, and rabbit anti-Lamin B1 monoclonal antibody were from Abcam (Cambridge, MA).

\section{Cell Culture}

RAW264.7 murine macrophage cells were obtained from Sigma Chemical, Co. Ltd. (St. Louis, MO) and cultured in undifferentiated RAW macrophages-conditioned medium as previously described (Liu et al., 2008; Li et al., 2018). Briefly, RAW264.7 cells were cultured in Dulbecco's modified Eagle's medium (DMEM), with $10 \%$ fetal bovine serum (FBS), $2 \mathrm{mM}$ of L-glutamine, 100 units $/ \mathrm{ml}$ penicillin, and $100 \mathrm{mg} / \mathrm{ml}$ streptomycin at $37^{\circ} \mathrm{C}$ in $5 \% \mathrm{CO}_{2}$. All incubations were performed in cells under the three or four passages. 
A<smiles>O=Cc1ccc(-c2oc3cc(O)cc(O)c3c(=O)c2O)c(O)c1</smiles>

Morin hydrate $(\mathrm{MH})$
B

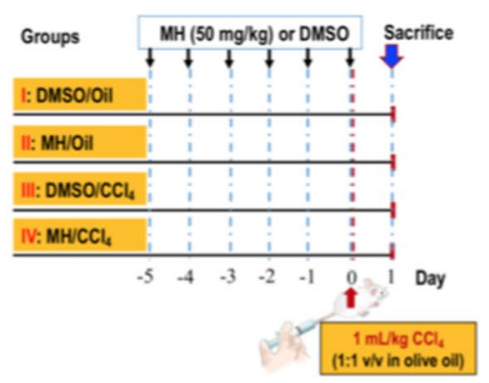

C



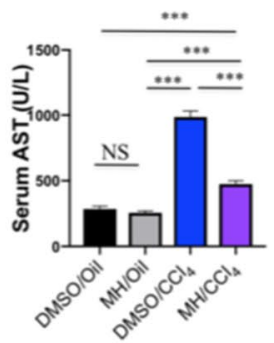

E

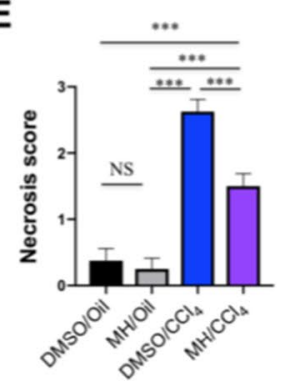

F

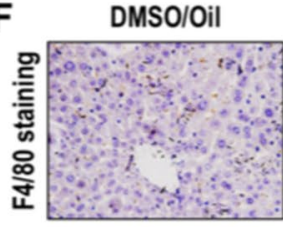

H
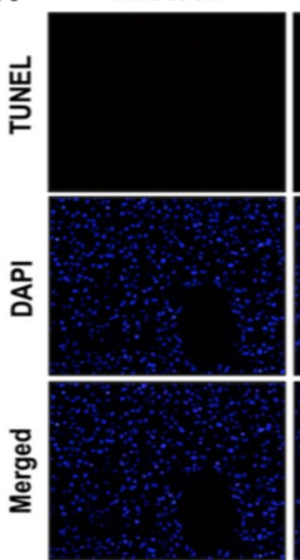

MH/Oil

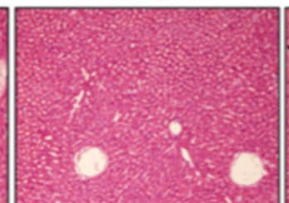

$\mathrm{DMSO} \mathrm{CCl}_{4}$

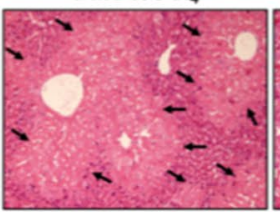

$\mathrm{MH} / \mathrm{CCl}_{4}$

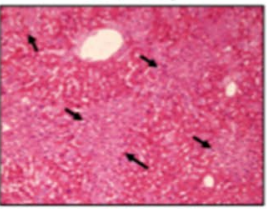

G

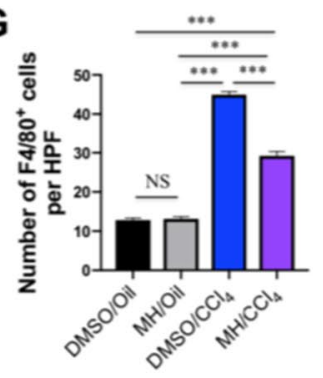

I

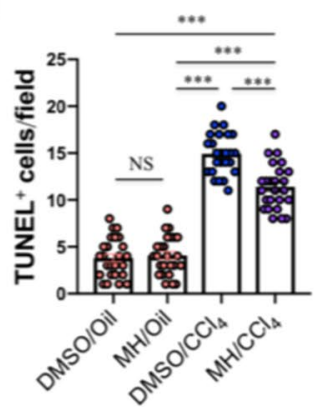

FIGURE 1 | Effect of morin hydrate (MH) on $\mathrm{CCl}_{4}$-induced liver injury in mice. (A) The molecular structure of $\mathrm{MH}\left(2^{\prime}, 3,4^{\prime}, 5,7-\right.$-pentahydroxyflavone). (B) Experimental study design. Mice were randomly divided into four groups, each consisting of eight animals. MH was dissolved in dimethyl sulfoxide (DMSO), and mice were orally given $50 \mathrm{mg} / \mathrm{kg}$ of $\mathrm{MH}$ once a day for five consecutive days before challenge with $\mathrm{CCl}_{4}$. To induce acute liver injury, a single dose of $1 \mathrm{ml} / \mathrm{kg} \mathrm{CCl}{ }_{4}$ (1:1 $\mathrm{V} / \mathrm{v}$ in olive oil) was injected intraperitoneally (i.p.) for 24 h. (C) Serum alanine transaminase (ALT) and aspartate transaminase (AST) levels in mice from each group. Data are expressed as mean \pm SEM ( $n=6$ for each group). (D) Histological examination of liver sections from each group with hematoxylin and eosin (H\&E) staining (original magnification, $\times 100)$. Black arrows indicate area of necrosis. (E) Necrosis was analyzed based on H\&E-stained liver sections and scored as described in the Material and Methods section ( $n=8$ for each group). (F) Immunohistochemical detection of F4/80-positive cells in liver sections from each group (original magnification: $\times 200$ ). (G) Quantification of F4/80-positive cells per high-power field (HPF) in liver sections from each group. Results mean of six fields and $n=5$ for each group. (H) TUNEL staining for apoptotic cells of the liver sections from each group of mice (original magnification, $\times 200$ ). (I) The quantification of TUNEL-positive cell number per HPF $(\times 400)$. Cells were counted five visual per liver sections from each group and $n=5$ for each group. ${ }^{\star \star \star} P<0.001$; NS indicates not significant. 


\section{Cell Viability Assays}

RAW264.7 cell viability was assessed by the MTT-based spectrophotometric methods. Cells were seeded in 96-well microtiter plates at a density of $2.5 \times 10^{5}$ cells/well. After $6 \mathrm{~h}$, the culture medium was replaced with serum-free medium containing $0.05 \%$ DMSO (vehicle) or various concentrations of $\mathrm{MH}(25,50$, and $100 \mu \mathrm{M})$ for $24 \mathrm{~h}$ at $37^{\circ} \mathrm{C}$ and $5 \% \mathrm{CO}_{2}$. Following treatment, cells were washed and incubated in $10 \%$ MTT, which was diluted in normal culture medium at $37^{\circ} \mathrm{C}$ until the visual color conversion occurred. Relative cytotoxicity was measured at 570-nm absorbance with FlexStation 3 multimode microplate reader (Molecular Device, Menlo Park, CA, USA). Cell viability was defined relative to vehicle-treated control, and the experiments were conducted three times independently.

For cell cultures, a stock of $\mathrm{MH}$ solution (10 mM) was prepared in DMSO and stored at $-20^{\circ} \mathrm{C}$. This stock solution was then further diluted in $0.05 \%$ DMSO before treatment of cells at the indicated concentrations; and these concentrations for cell treatment was based on previous in vitro bioactivity work (MadanKumar et al., 2014; Perumal et al., 2017).

\section{Cell Treatment Protocol}

In experiments assessing the effects of $\mathrm{MH}$ on macrophage activation, LPS (100 ng/ml) was used to induce the inflammatory response in RAW264.7 cells as previously reported (Liu et al., 2008). Firstly, the timing of LPS for activating RAW264.7 cells was assessed. Then, cells were stimulated with LPS and cultured with treatment of $\mathrm{MH}(25,50$, and $100 \mu \mathrm{M})$ for $24 \mathrm{~h}$ at $37^{\circ} \mathrm{C}$; parallel cultures were treated with an equivalent volume of vehicle for use as negative controls. Following treatment, TNF- $\alpha$ and IL- $1 \beta$ levels in the supernatants were quantified using commercial ELISA kits according to the manufacturer's instructions. Each sample was tested in duplicate.

To further assess the effect of $\mathrm{MH}$ on TREM-1-mediated inflammatory response, RAW264.7 cells were exposed to LPS for $24 \mathrm{~h}$ in the presence or absence of $\mathrm{MH}(50 \mu \mathrm{M})$. Finally, cells were washed and collected by centrifugation for RNA harvesting and protein isolation for assessing the expression of TREM-1 and its downstream molecules. All measurements were performed in triplicate wells.

\section{Small Interfering RNA Transfection in RAW264.7 Cells}

The TREM-1 small interfering RNA (siRNA) (siTREM-1) and non-targeted scrambled control siRNA (siNTC) were purchased from Santa Cruz Biotechnology (Delaware, CA, USA). Transient knockdown assays were performed using Lipofectamine 2000 (Invivogen, San Diego, CA, USA) according to the manufacturer's instructions. Briefly, the cells were normally seeded into 6-well culture plates $24 \mathrm{~h}$ prior to transfection. Once the cells had reached $60-80 \%$ confluence, the cells were transfected using Lipofectamine 2000 and with $20 \mathrm{pmol} / \mathrm{ml}$ siRNAs, as follows: control group, siNTC group, and siTREM-1 group. Knockdown efficiency was determined by quantitative reverse transcriptasepolymerase chain reaction (RT-PCR) and western blotting. After
RAW264.7 cells were transfected with siNTC or siTREM-1 for $48 \mathrm{~h}$, cells were treated with $100 \mathrm{ng} / \mathrm{ml}$ LPS for $24 \mathrm{~h}$ in the presence of $\mathrm{MH}(50 \mu \mathrm{M})$ or vehicle; the control group was not transfected or treated with LPS. Afterwards, cells were collected to assess the corresponding indicators.

\section{Animals and Experimental Design}

Pathogen-free male C57BL/6 mice (age, 6-8 weeks; body weight, 22 25 g) were obtained from Shanghai Laboratory Animal Research Center (Shanghai, China). Mice were kept in an environmentally controlled room $\left(23 \pm 2^{\circ} \mathrm{C}, 55 \pm 10 \%\right.$ humidity $)$ with a 12-h light-and-dark cycle and allowed free access to food and water. The study was performed in accordance with the Guiding Principles for the Care and Use of Laboratory Animals and approved by the Fudan University Animal Care Committee. Experimental design is outlined in Figure 1B. $\mathrm{MH}$ was dissolved in DMSO, and mice were orally given $50 \mathrm{mg} / \mathrm{kg}$ of $\mathrm{MH}$ once a day for five consecutive days before challenge with $\mathrm{CCl}_{4}$. The dosage of $\mathrm{MH}$ was chosen according to previous studies in mice (Lee et al., 2016; Naowaboot et al., 2016). For the induction of acute liver injury, a single dose of $1 \mathrm{ml} / \mathrm{kg} \mathrm{CCl}(1: 1 \mathrm{v} / \mathrm{v}$ in olive oil) was injected intraperitoneally (i.p.) in C57BL/6 mice. Mice were randomly divided into four groups, each consisting of eight animals. The groups were as follows: Group I was the normal control in which mice were not treated with either $\mathrm{CCl}_{4}$ or $\mathrm{MH}$ but were given an equal volume olive oil (i.p.) and orally administered with an equal volume of DMSO; Group II was $\mathrm{MH}$-treated control, and mice were given $\mathrm{MH}$ orally and injected with olive oil; Group III mice were injected with $\mathrm{CCl}_{4}$ and administered with an equal volume of DMSO for 5 days; and Group IV was $\mathrm{MH}$-pretreated group in which mice were given morin for 5 days before challenge with $\mathrm{CCl}_{4}$. All mice were sacrificed at $24 \mathrm{~h}$ after $\mathrm{CCl}_{4}$ injection, blood was collected, and liver samples were harvested upon euthanasia.

\section{Assay for Serum AST and ALT Levels}

Levels of serum aspartate transaminase (AST) and alanine transaminase (ALT) were determined with a commercial assay kit according to the manufacturer's recommendations (Nanjing Jiancheng Biological Technology, Inc., Nanjing, China). Liver enzyme activities were shown in international unit per liter (U/L).

\section{Estimation of Oxidative Stress and Antioxidant Property in the Liver}

The liver of each mice was isolated, washed, and perfused with chilled normal saline. Approximately $1 \mathrm{~g}$ was minced and homogenized in ice-cold phosphate buffer ( $140 \mathrm{mM}$ of $\mathrm{KCl}, 20 \mathrm{nM}$ of phosphate, and $\mathrm{pH} 7.4$ ). The homogenate was centrifuged at $1,500 \mathrm{~g}$ for $15 \mathrm{~min}$ at $4^{\circ} \mathrm{C}$. The supernatant was used for the estimation of lipid peroxidation and oxidative stress markers.

MDA formation in mouse livers by lipid peroxidation MDA assay kit according to the protocol provided by the manufacturer. MDA levels were calculated using the standard curve of MDA, and its level is expressed in $\mathrm{nmol} / \mathrm{mg}$ of protein liver tissue. Total glutathione (GSH plus oxidized glutathione (GSSG)) and 
GSH were determined using total glutathione assay kit, and total SOD activity was estimated using total SOD assay kit with NBT according to the protocol provided by the manufacturer. GSH and GSSG activities were expressed as $\mathrm{nmol} / \mathrm{mg}$ of protein, and SOD activity was expressed as U/mg of protein.

\section{Analysis of Liver Histopathology}

For histological analysis, liver tissue specimens were fixed in 10\% buffered formalin and embedded in paraffin, cut at thicknesses of $4 \mu \mathrm{m}$, and then stained with hematoxylin and eosin (H\&E) according to standard procedure. Necrosis in the liver sections was assessed by a registered pathologist in a blinded manner and graded by a semiquantitative score from 0 to 3 as described previously (Horrillo et al., 2007).

\section{Immunohistochemistry and Analysis of Histological Markers}

The liver tissue sections were dewaxed, hydrated, and pretreated with the heat-induced antigen retrieval technique. Sections were blocked and then incubated with the respective primary antibody as described previously ( $\mathrm{Li}$ et al., 2018). Primary antibodies were incubated on the sections overnight at $4^{\circ} \mathrm{C}$ at the following concentrations: TREM-1 antibody, 1:100; TLR4 antibody, 1:50; and F4/80 antibody, 1:50. All antibodies were diluted in Trisbuffered saline (TBS)-2\% bovine serum albumin. Negativecontrol antibodies consisted of species-matched and, where appropriate, Ig G (IgG) subclass-matched Ig fractions, used at the same dilution as the secondary antibodies. Color development was induced using 3,3'-diaminobenzidine (DAB) tetrachloride during an incubation period of 5 to $10 \mathrm{~min}$. With the use of this substrate, specific staining was visualized by light microscopy.

For quantification of the numbers of liver macrophages and TREM-1-positive cells in sections, six non-overlapping randomly selected fields of view per slide at $\times 400$ magnifications were examined; and five mice of each group were examined. The result was expressed as the number of F4/80+ cells or TREM-1 ${ }^{+}$ cells per high-power field (HPF) (Li et al., 2018).

\section{Detection of Cell Death by TUNEL Staining}

TUNEL (terminal deoxynucleotidyl transferase mediated dUTP nick-end labeling) staining was performed to assess death hepatocytes in liver sections. Formalin-fixed, paraffinembedded tissue sections were stained by using a One-step TUNEL Apoptosis Detection Kit (Alexa Fluor 647, YEASEN, Shanghai, China) according to the manufacturer's instructions. Finally, slides were counterstained with DAPI and hematoxylin solution. The number of TUNEL-positive cells (red) was counted on five fields of $\times 400$ magnification per slide, and five mice of each group were examined. The results were expressed as the mean number of TUNEL-positive cells.

\section{Quantitative Real-Time PCR Analysis}

RNA was extracted from frozen liver tissues and RAW264.7 cells using TRIzol reagent following the manufacturer's protocol. RNA was extracted and reverse transcribed with random hexamers and avian myeloblastosis virus reverse transcriptase using a commercial kit (Perfect Real Time, SYBR ${ }^{\circledR}$ PrimeScriP ${ }^{\mathrm{TM}}$, TaKaRa, Japan). Quantitative RT-PCR was performed for assessment of gene expression using ABI Prism 7500 Sequence Detection system (Applied Biosystems, Tokyo, Japan). The relative changes were normalized to GAPDH mRNA using the formula $2^{-\Delta \Delta \mathrm{Ct}}$, where $\Delta \Delta \mathrm{Ct}$ represents $\Delta \mathrm{Ct}$ values normalized with the mean $\Delta \mathrm{Ct}$ of control samples as described previously (Li et al., 2016a; Li et al., 2018). Sequences for target genes were purchased from Sangon Biotech Co., Ltd. (Shanghai, China) and are listed in Table 1.

\section{Isolation of Cytoplasmic and Nuclear Proteins}

To obtain cytoplasmic and nuclear fractions from whole liver tissue or cultured cells, nuclear and cytoplasmic proteins were prepared as described before (Li et al., 2016a; Li et al., 2018). In brief, nuclear and cytosolic proteins were extracted using NE-PER ${ }^{\circledR}$ (Pierce Biotechnology, Rockford, IL, USA) according to manufacturer's instructions. Protein concentrations were measured using Bicinchoninic Acid Protein Colorimetric Assay kits (BMI, Shanghai, China) with bovine serum albumin as standard.

\section{Western Blot Analysis}

Western blots were used to assess levels of expression of

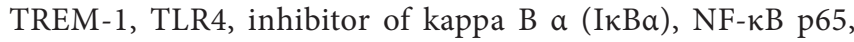
nuclear factor erythroid 2-related factor 2 (Nrf2), and heme

TABLE 1 | Mouse primer sequences used for quantitative real-time PCR.

\begin{tabular}{|c|c|c|}
\hline Target gene & Forward primers $\left(5^{\prime}-3^{\prime}\right)$ & Reverse primers $\left(5^{\prime}-3^{\prime}\right)$ \\
\hline TLR4 & CCTGAGCAAACAGCAGAGGA & CCATGTGTTCCATGGGCTCT \\
\hline $\mathrm{HO}-1$ & AGCCCCACCAAGTTCAAACA & TCTCTGCAGGGGCAGTATCT \\
\hline Nrf2 & TCTCCTAGTTCTCCGCTGCT & TGGTGTCTGTCTGGATGTGC \\
\hline TNF- $\alpha$ & GGACTAGCCAGGAGGGAGAA & CGCGGATCATGCTITCTGTG \\
\hline 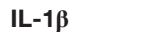 & ACCTAGCTGTCAACGTGTGG & TCAAAGCAATGTGCTGGTGC \\
\hline TREM-1 & TCCTATTACAAGGCTGACAGAGCGTC & AAGACCAGGAGAGGAAACAACCGC \\
\hline IL-6 & GGAGTCACAGAAGGAGTGGC & CGCACTAGGTITGCCGAGTA \\
\hline GAPDH & CTCGTGGTTCACACCCATCA & CTCGTGGTTCACACCCATCA \\
\hline
\end{tabular}

PCR, polymerase chain reaction; TLR4, toll-like receptor 4; HO-1, heme oxygenase-1; Nrf2, nuclear factor erythroid 2-related factor 2; TNF- $\alpha$, tumor necrosis factor $\alpha$; IL, interleukin; TREM-1, triggering receptor expressed on myeloid cells-1. 
oxygenase-1 (HO-1) subunit proteins. Samples $(30 \mu \mathrm{g}$ of protein/lane) were separated by sodium dodecyl sulfatepolyacrylamide electrophoresis (SDS-PAGE) and transferred to polyvinylidene difluoride (PVDF) membranes. After blockade of nonspecific binding sites with $5 \%(\mathrm{w} / \mathrm{v})$ non-fat milk power for $1 \mathrm{~h}$, membranes were washed with TBST and subsequently incubated in Tween phosphate-buffered saline at $4^{\circ} \mathrm{C}$ for $24 \mathrm{~h}$ with the following primary antibodies: TREM-1 antibody (1:1,000 dilution), TLR4 antibody (1:1,500), IкBa antibody (1:2,000), NF- $\mathrm{BB} / \mathrm{p} 65$ antibody $(1: 2,500)$, Nrf2 antibody (1:2,000), and HO-1 antibody (1:1,500). Thereafter, the membranes were washed by TBS/Tween followed by incubation with corresponding secondary antibody for $2 \mathrm{~h}$ at room temperature. Protein bands were visualized using ECL substrate (Bio-Rad Laboratories) according to the instructions of the manufacturer. Membranes were also incubated with antibodies against GAPDH (1:5,000 dilution) and Lamin B1 (1:3,000), as internal controls for cytosolic and nuclear proteins, respectively. Densities were quantified using Image J software (NIH, Bethesda, Maryland, USA).

\section{Statistical Analysis}

All data are expressed as the mean \pm standard error of mean (SEM), unless otherwise stated. Statistical analyses were performed using GraphPad Prism 8 statistical software (La Jolla, CA, USA). Comparisons among three or more groups were performed by one-way analysis of variance (ANOVA) with post-hoc Tukey's multiple comparison tests or by twotailed unpaired Student's $t$-tests. Comparisons between two independent groups were performed using a two-sample $t$-test. For all analyses, $P$-values of less than 0.05 were considered to be statistical significance.

\section{RESULTS}

\section{Effect of $\mathrm{MH}$ on $\mathrm{CCl}_{4}$-Induced Liver Injury in Mice}

The protective effect of $\mathrm{MH}$ against acute liver injury was confirmed by analysis of serum aminotransferase levels and histopathological findings by $\mathrm{H} \& \mathrm{E}$ staining. As shown in Figure 1C, compared with those in DMSO/oil or $\mathrm{MH}$ /oil group mice, the levels of serum ALT and AST significantly increased in response to $\mathrm{CCl}_{4}$ injection in mice; however, $\mathrm{CCl}_{4}$-injected mice with $\mathrm{MH}(50 \mathrm{mg} / \mathrm{kg}$ ) pretreatment remarkably inhibited the levels of the two transaminases than in those mice with vehicle pretreatment. Notably, pretreatment of mice with $\mathrm{MH}$ alone for 5 days did not show any significant influence in liver enzymes than did the DMSO/oil group mice, which signified a nontoxic effect of $\mathrm{MH}$ at this dosage on the liver from mice. Furthermore, serum aminotransferase levels paralleled the histopathological alterations. As shown in Figure 1D, liver sections from the oil-treated control mice receiving DMSO or $\mathrm{MH}$ showed normal cellular architecture and did not display any hepatocyte necrosis with distinct hepatic cells and sinusoidal spaces. In contrast, the $\mathrm{CCl}_{4}$-exposed groups exhibited obvious destruction of hepatic lobule structure, hyperemia, inflammatory infiltration, and large areas of necrosis within the liver lobules. However, pretreatment with $\mathrm{MH}$ of $\mathrm{CCl}_{4}$-injected mice dramatically alleviated liver inflammation and hepatocyte necrosis than did vehicle pretreated to those mice (Figure 1D). These findings were validated by the scores for necrosis in livers (Figure 1E).

To further confirm that $\mathrm{MH}$ suppressed hepatic inflammation in acute liver injury in mice, we analyzed the macrophage infiltration in injured liver by immunostaining with an antibody against F4/80. Our results demonstrated that F4/80-positive macrophages were detected in sinusoids of both the DMSO/ oil group and $\mathrm{MH} /$ oil group. Notably, a massive accumulation of F4/80-positive macrophages could be observed in injured livers from mice induced by $\mathrm{CCl}_{4}$. However, this increase in macrophages recruitment in livers was remarkably reduced by pretreatment with $\mathrm{MH}$ (Figure 1F). Consistent with this observation, the number of F4/80 staining cells per HPF obviously increased in the liver of mice induced by $\mathrm{CCl}_{4}$, and this increase was significantly lower in $\mathrm{MH}$-treated injured mice than in vehicle-treated mice $(29.23 \pm 1.05 / \mathrm{HPF}$ vs. $44.97 \pm 0.76 /$ HPF, $P<0.001$; Figure 1G).

Moreover, we used TUNEL assay to assess the effect of $\mathrm{MH}$ on the hepatocyte death in the liver after challenge $\mathrm{CCl}_{4}$. As shown in Figures $\mathbf{1 H}, \mathbf{I}, \mathrm{CCl}_{4}$ injection markedly increased the number of hepatocytes apoptosis than in the oil-treated groups. However, the number of TUNEL-positive cells in $\mathrm{MH} / \mathrm{CCl}_{4}$ group was significantly decreased as compared with that in the $\mathrm{DMSO} / \mathrm{CCl}_{4}$ group.

On the whole, our results demonstrated that pretreatment with $\mathrm{MH}$ mitigated $\mathrm{CCl}_{4}$-induced liver injury, inflammation, and cell death in mice.

\section{Effect of MH on TREM-1 Expression in Livers From Mice Induced With $\mathbf{C C l}_{4}$}

Expression and localization of TREM-1 in livers of mice from each group were determined by immunohistochemistry. As shown in Figure 2A, immunostaining of livers from oil-treated control mice revealed that TREM-1 has weak signals and was localized predominantly in the sinusoids. In contrast, $24 \mathrm{~h}$ after injection of $\mathrm{CCl}_{4}$, greater TREM-1 immunoreactivity was observed in the periportal areas and necrotic areas of the liver. However, pretreatment with $\mathrm{MH}$ of $\mathrm{CCl}_{4}$-injected mice remarkably decreased the immunoreactivity of TREM-1 in the sinusoids than did pretreatment with DMSO in mice (Figure 2A). Consistent with this finding, $\mathrm{CCl}_{4}$ injection obviously increased the number of TREM-1 staining cells per HPF, and the increase was significantly lower in $\mathrm{MH}$-treated injured mice than in DMSO-treated mice (Figure 2B). Furthermore, our western blotting revealed that pretreatment with $50 \mathrm{mg} / \mathrm{kg} \mathrm{MH}$ of $\mathrm{CCl}_{4}$-injected mice significantly reduced the levels of TREM-1 protein expression than did pretreatment with DMSO of those animals (Figure 2C). In addition, intrahepatic expression of TREM-1 mRNA was also elevated at $24 \mathrm{~h}$ after $\mathrm{CCl}_{4}$ injection, but this gene was reduced remarkably in $\mathrm{MH}$-pretreated than in DMSO-pretreated mice induced by $\mathrm{CCl}_{4}$ (Figure 2D). 


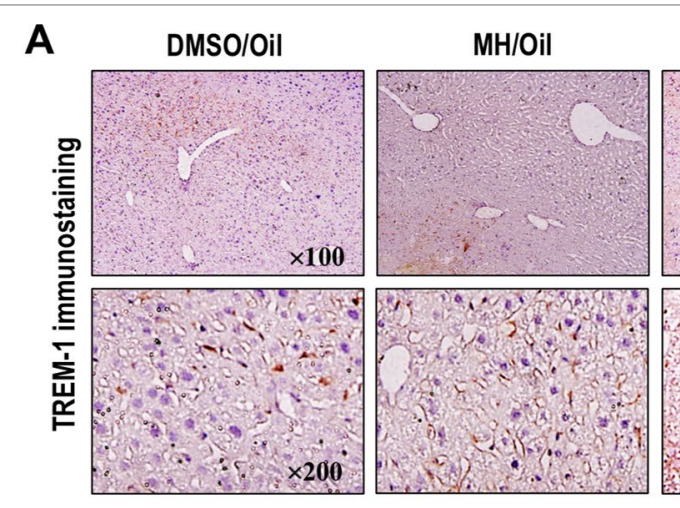

B



C

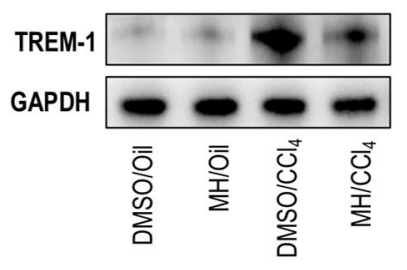



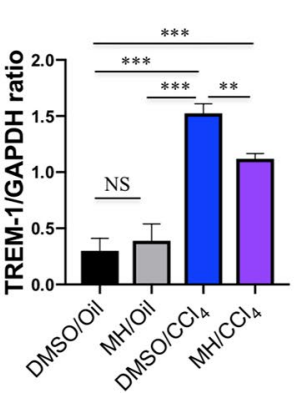

$\mathrm{MH} / \mathrm{CCl}_{4}$

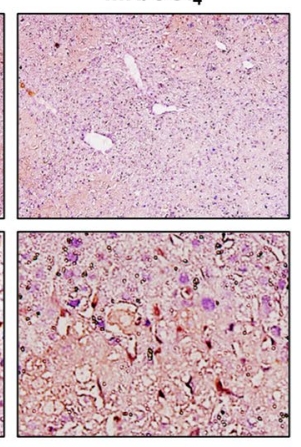

D

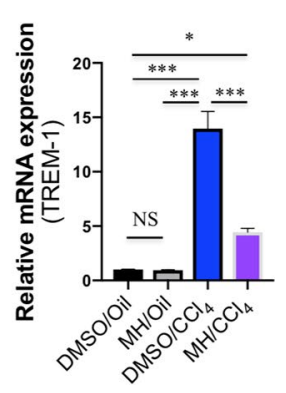

FIGURE 2 | Effect of morin hydrate (MH) on triggering receptor expressed on myeloid cells-1 (TREM-1) expression in livers from mice induced by CCI . (A) Expression of TREM-1 in the liver was determined by immunohistochemistry. Original magnification, ×100 (upper column) and ×200 (lower column).

(B) Quantification of TREM-1-positive cells per high-power field (HPF) in liver sections from each group. Results mean of six fields and $n=5$ for each group.

(C) Western blot analysis of TREM-1 protein in liver lysates from each group; results normalized relative to expression of GAPDH. (D) Hepatic TREM-1 mRNA expression was measured by quantitative reverse transcriptase-polymerase chain reaction (RT-PCR). Results are shown as fold change compared with dimethyl sulfoxide (DMSO/oil group and GAPDH serving as loading control $(n=5)$. ${ }^{\star} P<0.05,{ }^{\star \star} P<0.01,{ }^{\star \star \star} P<0.001$. NS indicates not significant.

Taken together, our data demonstrated that $\mathrm{MH}$ inhibited TREM-1 expression in injured livers of mice induced by $\mathrm{CCl}_{4}$.

\section{Effect of MH on TLR4 Expression and Localization in the Liver of $\mathrm{CCl}_{4}$-Treated Mice}

Because TREM-1 is reported to amplify the inflammatory response initiated by TLR engagement (Ornatowska et al., 2007; Tammaro et al., 2017), we further investigated whether TLR4 signaling was inhibited by $\mathrm{MH}$ in acute liver injury. As shown in Figure 3A, immunohistochemistry showed that the liver sections from oiltreated control mice showed weak constitutive expression of TLR4 on vascular and sinusoidal endothelial cells and no expression on hepatocytes, similar to our previous studies (Li et al., 2016a; Li et al., 2016b). TLR4 expression signaling was increased on vascular, sinusoidal endothelial cells and hepatocytes after $\mathrm{CCl}_{4}$ injection, but overall TLR4 immunoreactivity was reduced by $\mathrm{MH}$ pretreatment when compared with DMSO-pretreated control (Figure 3A). Consistent with this result, pretreatment with $\mathrm{MH}$ of $\mathrm{CCl}_{4}$-injected mice significantly reduced the levels of TLR4 protein expression than in vehicle-pretreated animals (Figure 3B). In addition, intrahepatic expression of TLR4 mRNA was also induced at $24 \mathrm{~h}$ after $\mathrm{CCl}_{4}$ injection, but this gene was reduced remarkably in $\mathrm{MH}$-pretreated than in DMSO-pretreated mice induced by $\mathrm{CCl}_{4}$ (Figure 3C).

\section{Effect of MH on NF-кB Nuclear Translocation and Proinflammatory Cytokines Expression in the Liver of $\mathrm{CCl}_{4}^{-}$ Treated Mice}

It is well established that NF- $\kappa \mathrm{B}$ is activated by the TLR signaling pathway. Thus, we examined the effect of $\mathrm{MH}$ on the activation of NF- $\mathrm{KB}$ in livers, and western blot analysis of the nuclear translocation of the NF- $\kappa \mathrm{B}$ p65 subunit was performed in liver tissues. Our results revealed that the level of nuclear NF- $\mathrm{BB}$ p65 in the liver was increased by $\mathrm{CCl}_{4}$ injection and that this change was inhibited by $\mathrm{MH}$ administration (Figure $4 \mathrm{~A}$ ). In contrast, $\mathrm{CCl}_{4}$ injection led to reduction in the level of cytosolic NF- $\kappa \mathrm{B}$ p65 in the liver, but this decrease was restored by $\mathrm{MH}$ administered to $\mathrm{CCl}_{4}$-injected mice (Figure $4 \mathrm{~B}$ ). Additionally, we also found that the intrahepatic level of I $\kappa \mathrm{Ba}$ in the cytosol was lower in the $\mathrm{CCl}_{4}$-treated than in DMSO/oil group, and this reduction was remarkably inhibited by $\mathrm{MH}$ pretreatment in $\mathrm{CCl}_{4}$-induced mice (Figure 4C). As the cytosolic I $\kappa \mathrm{B} a$ was associated with NF- $\kappa \mathrm{B}$ translocation from cytosol to nuclear, this result confirmed that $\mathrm{MH}$ inhibited nuclear translocation of NF- $\kappa \mathrm{B}$ p 65 with reduced intrahepatic I $\kappa \mathrm{B} a$ degradation.

The transcription factor NF- $\kappa \mathrm{B}$ plays an important role in the inflammatory response as NF- $\mathrm{BB}$ activation can activate the transcription of various proinflammatory genes and regulate inflammation (Seki et al., 2007). Therefore, the expression of 


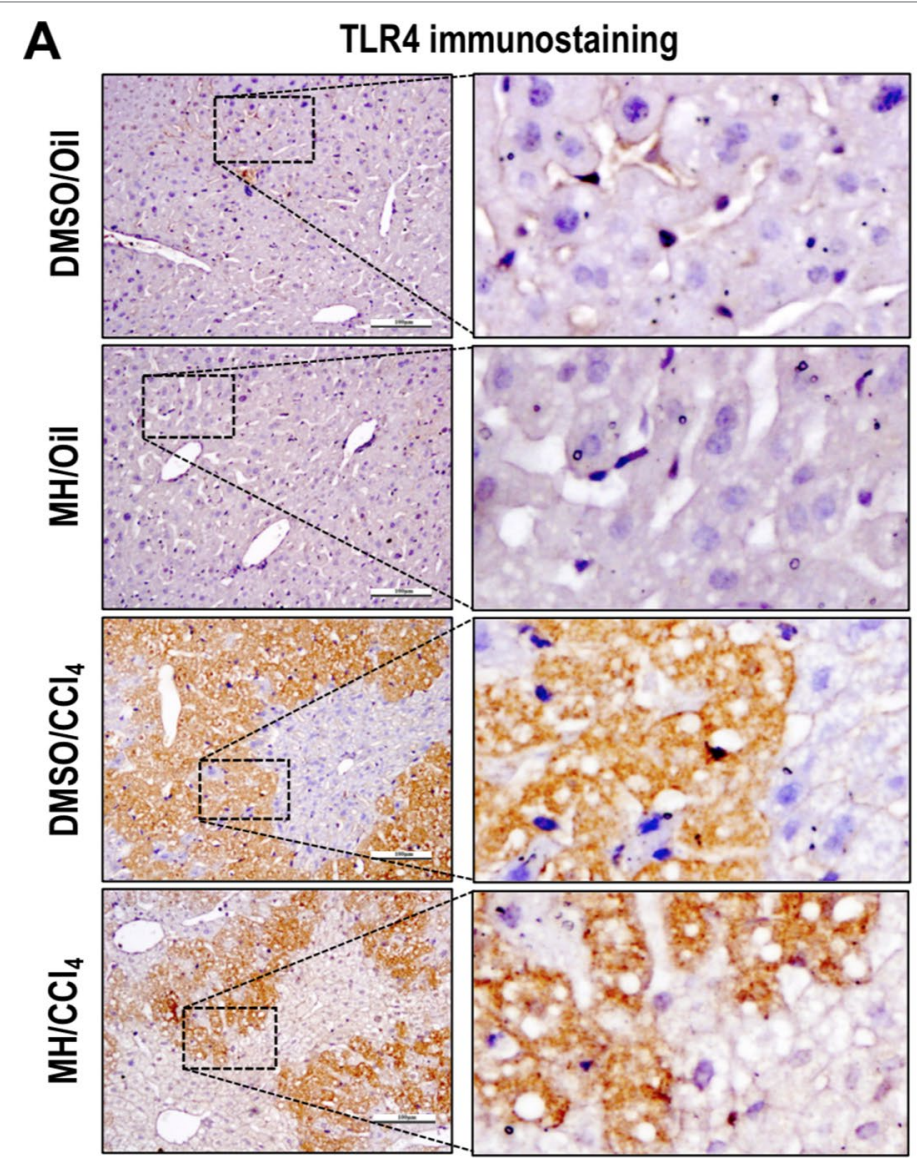

B

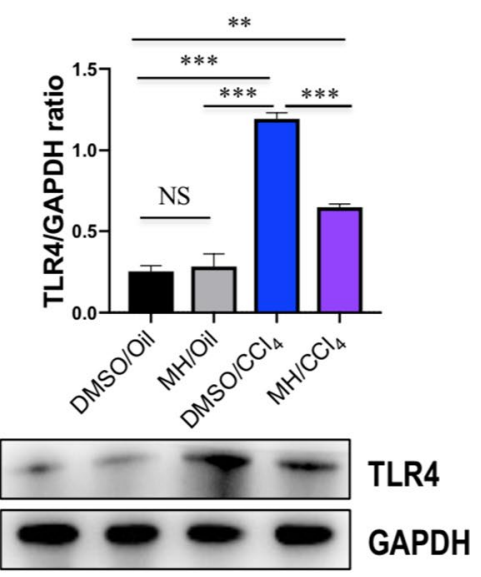

C.

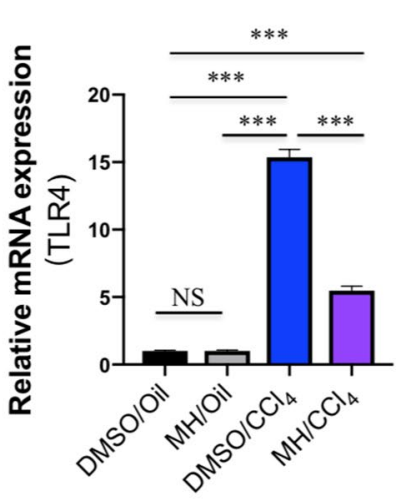

FIGURE 3 | Effect of morin hydrate (MH) on toll-like receptor 4 (TLR4) expression and localization in the liver of $\mathrm{CCl}_{4}$-treated mice. (A) Expression and distribution of TLR4 in the liver were determined by immunohistochemistry. Original magnification, $\times 200$ (left column) and $\times 400$ (right column). Boxed regions in the left column were enlarged. (B) Western blot analysis of TLR4 protein of liver tissue samples; results normalized relative to expression of GAPDH. (C) Hepatic TLR4 mRNA expression was measured by quantitative reverse transcriptase-polymerase chain reaction (RT-PCR). Results are shown as fold change compared with dimethyl sulfoxide (DMSO)/oil group and GAPDH served as loading control $(n=5) .{ }^{\star \star} P<0.01,{ }^{\star \star \star} P<0.001$. NS indicates not significant.

hepatic proinflammatory cytokines such as TNF- $\alpha$, IL- $1 \beta$, and IL- 6 mRNA was also assayed by quantitative RT-PCR. As shown in Figure 4D, the levels of TNF- $\alpha$, IL- $1 \beta$, and IL- 6 mRNA in livers increased significantly in response to $\mathrm{CCl}_{4}$ challenge, while $\mathrm{MH}$ pretreatment remarkably suppressed the increase of those genes in the liver.

Taken together, these results indicated that pretreatment with $\mathrm{MH}$ markedly mitigated $\mathrm{CCl}_{4}$-induced liver injury through inhibition of TLR4/NF- $\mathrm{BB}$-mediated inflammatory response.

\section{Effect of MH on the Production of Proinflammatory Cytokines in LPS- Stimulated RAW264.7 Cells}

To study the mechanisms underlying the anti-inflammatory effects mediated by MH, RAW264.7 murine macrophage cells were treated with LPS and various concentrations of MH. As expected, LPS-activated RAW264.7 cells resulted in a significant increase in the production of TNF- $\alpha$ and IL- $1 \beta$ cytokines. However, those mediators of the inflammatory response were remarkably inhibited by $\mathrm{MH}$ in a dose-dependent manner (Figures 5A, B). In addition, to avoid any cytotoxic effects of $\mathrm{MH}$, the cytotoxicity of $\mathrm{MH}$ was assessed; and our result demonstrated that cell viability was unaffected by those $\mathrm{MH}$ concentrations as confirmed by MTT assay (Figure 5C). Therefore, the concentration of $\mathrm{MH}$ at $50 \mu \mathrm{M}$ was used for the following study.

\section{Effect of MH on the TREM-1/TLR4 Signaling Molecules From LPS-Stimulated RAW264.7 Cells}

To identify the effects of TREM-1 on inflammatory response, RAW264.7 cells were stimulated with LPS for different time points. As shown in Figure 6A, our result revealed that the level of TREM-1 protein was gradually upregulated in RAW264.7 cells in response to LPS in a time-dependent manner. To investigate the effect of MH on TREM-1 expression in LPS-stimulated macrophages, RAW264.7 macrophages were stimulated in vitro with $\mathrm{MH}(50 \mu \mathrm{M})$ and LPS $(100 \mathrm{ng} / \mathrm{ml})$ or DMSO for $24 \mathrm{~h}$. The result in this study revealed that the expression of TREM-1 gene was increased obviously in cells after stimulation with LPS than in the cells with vehicle. However, $\mathrm{MH}$ treatment significantly 

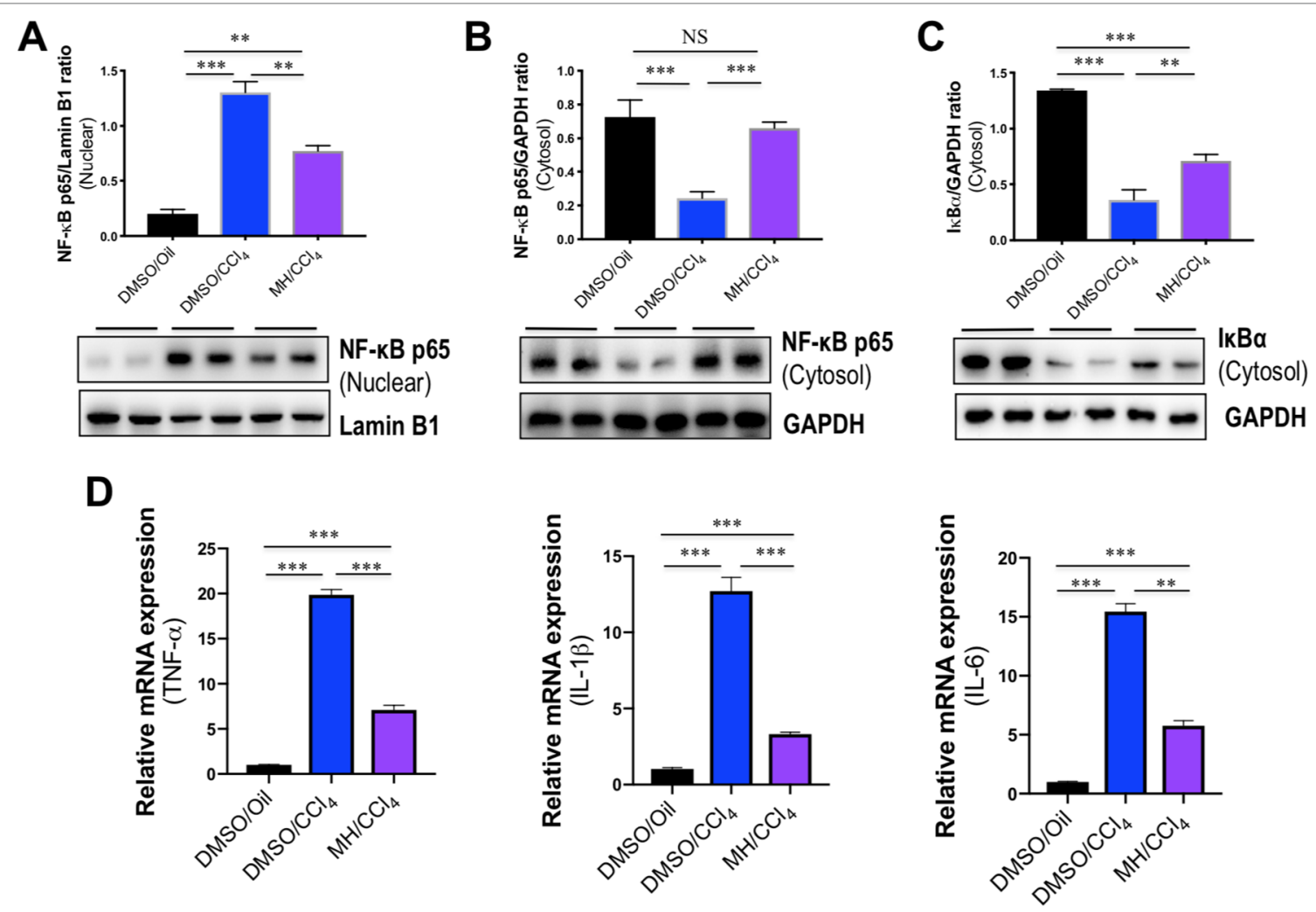

FIGURE 4 | Effect of morin hydrate (MH) on $\mathrm{CCl}_{4}$-induced nuclear factor-kappa B (NF-kB) translocation and proinflammatory cytokine expression in the liver. (A) Western blot analysis of NF-kB p65 in the nuclear fractions of liver tissue; results normalized relative to expression of Lamin B1. (B) Western blot analysis of NF-kB p65 protein in the cytosolic fractions of liver tissue; results normalized relative to expression of GAPDH. (C) Western blot analysis of I-kB $\alpha$ protein in the cytosolic fractions of liver tissue samples; results normalized relative to expression of GAPDH. (D) Hepatic proinflammatory cytokine gene of tumor necrosis factor $\alpha(T N F-\alpha)$, interleukin (IL)-1 $\beta$, and IL-6 was determined by quantitative reverse transcriptase-polymerase chain reaction (RT-PCR), and results are shown as fold change compared with dimethyl sulfoxide (DMSO)/oil group and GAPDH served as loading control $(n=5) .{ }^{* \star} P<0.01,{ }^{* \star *} P<0.001$. NS indicates not significant.

A

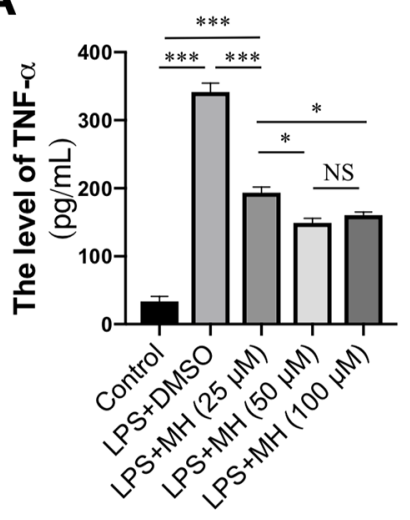

B

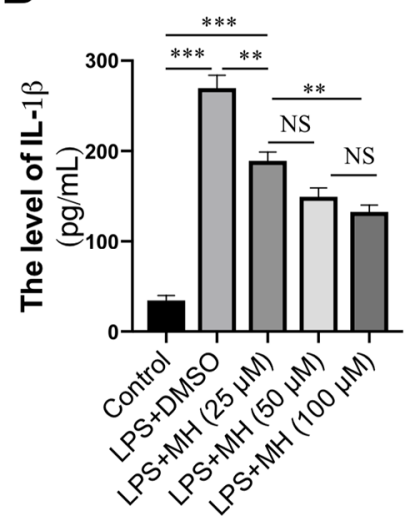

C

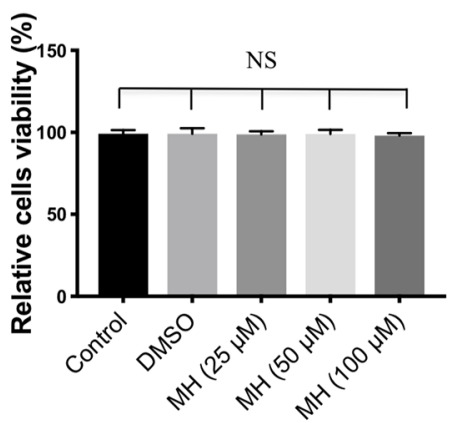

FIGURE 5 | Effect of morin hydrate (MH) on the production of proinflammatory cytokines in lipopolysaccharide (LPS)-stimulated RAW264.7 cells. RAW264.7 cells were treated with 25,50 , and $100 \mu \mathrm{M}$ of MH and co-cultured with or without LPS. (A-B) The level of TNF- $\alpha$ and IL- $1 \beta$ in the supernatants was measured by enzyme-linked immunosorbent assay (ELISA). Data are expressed as mean \pm SEM from three independent experiments. (C) RAW264.7 cells were treated with various concentrations of $\mathrm{MH}(25,50$, and $100 \mu \mathrm{M})$ for $24 \mathrm{~h}$, and cell viability was assessed by MTT assay. ${ }^{\star} P<0.05,{ }^{* \star} P<0.01,{ }^{* \star *} P<0.001$. NS indicates not significant. 

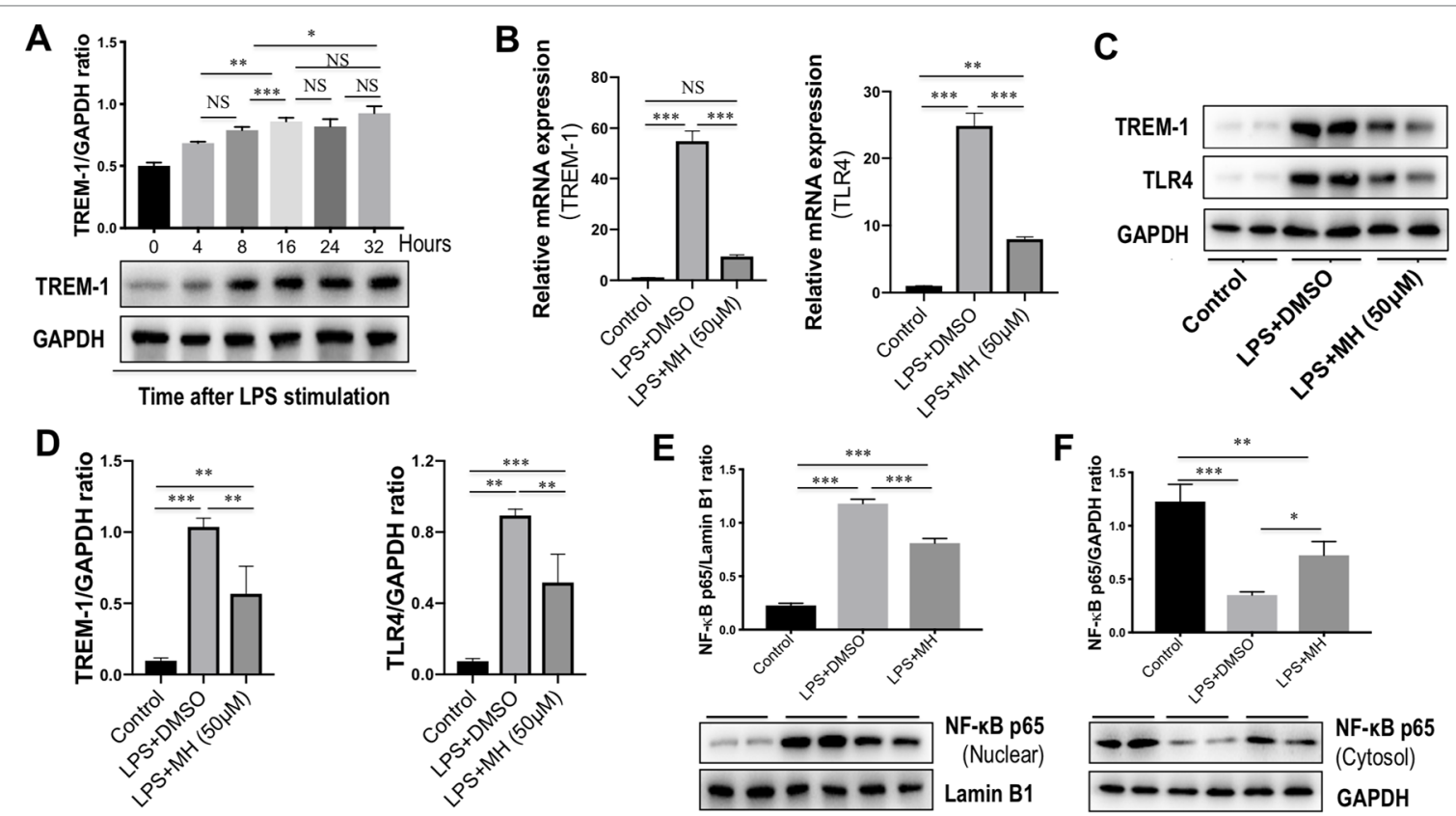

FIGURE 6 | Effect of morin hydrate (MH) on the triggering receptor expressed on myeloid cells-1 (TREM-1)/toll-like receptor 4 (TLR4) signaling molecules in lipopolysaccharide (LPS)-stimulated macrophages. (A) RAW264.7 cells were stimulated with LPS (100 ng/ml) and collected at the indicated time points. TREM-1 expression was assessed using western blot; results normalized relative to expression of GAPDH. (B) RAW264.7 cells were stimulated with LPS (100 ng/ml) and treated with $\mathrm{MH}(50 \mu \mathrm{M})$ or vehicle (DMSO) for $24 \mathrm{~h}$; and quantification reverse transcriptase-polymerase chain reaction (RT-PCR) for TREM-1 and TLR4 mRNA expression. (C, D) Western blot analysis of TREM-1 and TLR4 protein levels; results normalized relative to expression of GAPDH. Blot shown is representative of three experiments with similar results. (E) Western blot analysis of NF-kB p65 in the nuclear fractions of RAW264.7 cells; results normalized relative to expression of Lamin B1. (F) Western blot analysis of NF-kB p65 protein in the cytosolic fractions of RAW264.7 cells; results normalized relative to expression of GAPDH. ${ }^{*} P<$ $0.05,{ }^{\star \star} P<0.01,{ }^{* \star *} P<0.001$. NS indicates not significant.

blocked LPS-induced TREM-1 gene expression on RAW264.7 cells (Figure 6B). Consistent with this result, our western blot analysis also demonstrated that LPS-treated macrophages in the presence of $\mathrm{MH}$ resulted in the decrease of TREM-1 protein levels than in DMSO-treated cells (Figures 6C, D). Similarly, as shown in Figures 6B-D, MH also remarkably downregulated the levels of the TLR4 gene and protein expression in LPSstimulated RAW264.7 cells in vitro. Furthermore, our results also demonstrated that LPS induced a remarkably increase of nuclear translocation of NF- $\mathrm{kB}$ p65 subunit in RAW264.7 cells. However, application of $\mathrm{MH}$ potently inhibited this translocation in vitro (Figures 6E, F).

\section{Effect of MH on the TREM-1/TLR4 Signaling Molecules From LPS-Stimulated RAW264.7 Cells After TREM-1 Knockdown}

To further determine the mechanisms by which MH suppressed the inflammatory response in macrophages through inhibition of TREM-1 signaling pathway, RAW264.7 cells were transfected with TREM-1-specific siRNA, and the knockdown of TREM-1 was confirmed by RT-PCR and western blot (Figures 7A, B). Then, the MH group and model group were stimulated by LPS $(100 \mathrm{ng} / \mathrm{mL})$ for $24 \mathrm{~h}$ with the presence of MH $(50 \mu \mathrm{M})$ or DMSO. Our result demonstrated that there was no difference between the siNTC + LPS + MH group and the siTREM-1 + LPS + DMSO group in expression of the TREM-1 and TLR4 mRNA (Figures 7C, D) and protein (Figures 7E, F). The mRNA and protein levels of TREM-1 and TLR4 in the siNTC + LPS + DMSO group were remarkably increased than in the siNTC + LPS + MH group. Of note, compared with the siTREM-1 + LPS + DMSO group, the levels of TREM- 1 and TLR4 in the siTREM- 1 + LPS + MH group were further decreased (Figures 7C-E). Taken together, these results indicated that $\mathrm{MH}$ could suppress TREM-1 and TLR4 expression in LPS-stimulated RAW264.7 cells, and this inhibitory effect had enhanced by TREM-1 knockdown.

\section{Effect of MH on Oxidative Stress in the Liver of $\mathrm{CCl}_{4}$-Treated Mice}

To determine the oxidative stress in our study, we evaluated the MDA formation in the liver as evidence of lipid peroxidation. The administration of $\mathrm{CCl}_{4}$ remarkedly increased hepatic MDA content, whether animals were pretreated with vehicle or $\mathrm{MH}$ (11.11 and $7.16 \mathrm{nmol} / \mathrm{mg}$ protein, respectively), than in the control mice $(0.25 \mathrm{nmol} / \mathrm{mg}$ protein). However, $\mathrm{MH}$ pretreatment led to a significant amelioration in $\mathrm{CCl}_{4}$-induced increase in hepatic MDA content (Figure 8A).

Liver GSH levels and SOD activity were measured as markers of oxidative stress at the hydrophilic level. Compared with normal control, administration of $\mathrm{CCl}_{4}$ significantly decreased the activity of SOD in the liver; however, those reductions were 

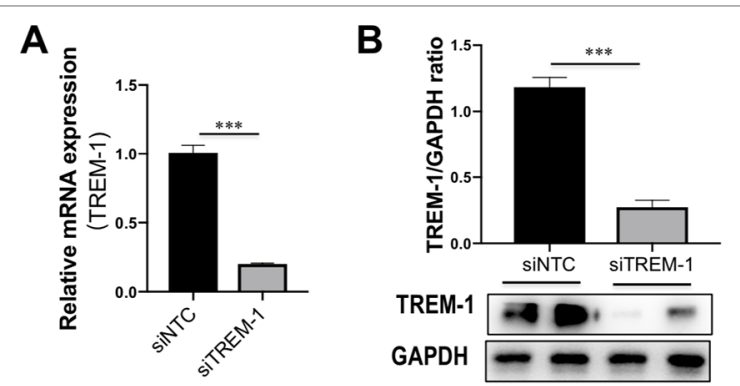
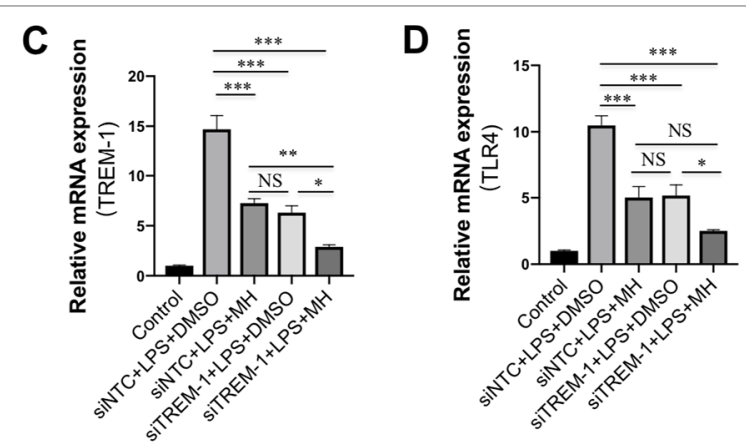

E

$\mathbf{F}$
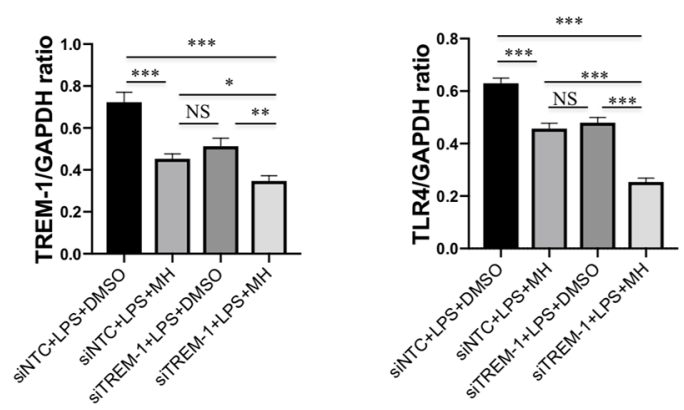

FIGURE 7 | Effect of morin hydrate (MH) on expression of the triggering receptor expressed on myeloid cells-1 (TREM-1) and toll-like receptor 4 (TLR4) in (LPS)stimulated macrophages after TREM-1 knockdown. (A, B) RAW264.7 cells that had been transfected with siNTC or siTREM-1 for 24 h, and then cells were treated for $24 \mathrm{~h}$ with $100 \mathrm{ng} / \mathrm{mL}$ LPS. The transfected effective was confirmed by assessing the gene (A) and protein expression (B). TREM-1 mRNA was assayed by quantitative reverse transcriptase-polymerase chain reaction (RT-PCR), and TREM-1 protein expression was examined by Western blot. (C, D) The levels of TREM-1 and TLR4 mRNA expression were determined by quantitative RT-PCR, and results are shown as fold change compared with control group and GAPDH served as loading control $(n=5)$. RAW264.7 cells had been transfected with siNTC or siTREM-1 and then treated for $24 \mathrm{~h}$ with $100 \mathrm{\mu g} / \mathrm{mL}$ LPS at the presence of $\mathrm{MH}(50 \mu \mathrm{M})$ or DMSO. (E, F) Western blot for TREM-1 and TLR4 protein expression. Representative blots are shown together with the corresponding densitometric quantification values, which were normalized based on GAPDH expression. RAW264.7 cells had been transfected with siNTC or siTREM-1 and then treated for $24 \mathrm{~h}$ with $100 \mu \mathrm{g} / \mathrm{mL}$ LPS at the presence of $\mathrm{MH}(50 \mu \mathrm{M})$ or DMSO. ${ }^{\star} P<0.05,{ }^{\star \star} P<0.01,{ }^{\star \star \star} P<0.001$. NS indicates not significant.

markedly restored by $\mathrm{MH}$ pretreatment in the liver of $\mathrm{CCl}_{4^{-}}$ treated mice when compared with vehicle-pretreated animals (12.61 vs. $18.98 \mathrm{U} / \mathrm{mg}$ protein) (Figure 8B). Similarly, $\mathrm{CCl}_{4^{-}}$ induced oxidative stress led to a significant decrease in hepatic GSH and GSSG in mice, while $\mathrm{MH}$ administration prevented the decrement in GSH induced by $\mathrm{CCl}_{4}$. Moreover, in the group receiving $\mathrm{CCl}_{4}$ and $\mathrm{MH}$, GSSG increased significantly (Figure 8C).

\section{Effect of MH on Nrf2/HO-1 Pathway in the Liver of $\mathrm{CCl}_{4}$-Treated Mice}

Nrf2 is a cellular sensor of oxidative stress, and Nrf2 is crucial for antioxidant response element (ARE)-mediated induction of detoxifying enzymes, anti-oxidative stress genes, and other target genes involved in cellular protection (Bataille and Manautou, 2012). To further determine the molecular mechanism of oxidative stress induced by $\mathrm{MH}$ in $\mathrm{CCl}_{4^{-}}$ induced liver injury, we firstly examined Nrf2 expression and translocation by western blotting; the result revealed that the level of nuclear $\mathrm{Nrf} 2$ expression was decreased in $\mathrm{CCl}_{4}$-exposed mice compared with the control mice but was remarkably increased in those mice pretreated with MH (Figure 8D). Similarly, the level of cytoplasmic Nrf2 expression was also decreased in the mice receiving $\mathrm{CCl}_{4}$ alone compared with the control mice. In contrast, the mice pretreatment with $\mathrm{MH}$ showed a higher level of cytoplasmic Nrf2 with respect to that in the mice of vehicle-treated control (Figure 8E). Simultaneously, we also assessed the Nrf2's downstream target HO-1 mRNA and protein expression by RT-PCR and western blot, respectively. As shown in Figures 8F, G, $\mathrm{CCl}_{4}$ administration led to decrease in the levels of HO-1 gene and protein expression in the injured liver as compared with normal control. However, pretreatment with $\mathrm{MH}(50 \mathrm{mg} / \mathrm{kg})$ of $\mathrm{CCl}_{4}$-injected mice led to a substantial induction of gene and protein expression of HO-1 in livers. Altogether, these results suggested that $\mathrm{MH}$ pretreatment could effectively upregulate the Nrf2 and HO-1 expression as well as promote nuclear translocation of $\mathrm{Nrf} 2$.

\section{DISCUSSION}

The present study provided further evidence to support that $\mathrm{MH}$ could protect against acute $\mathrm{CCl}_{4}$-induced liver damage by inhibiting TREM-1-mediated inflammatory response and attenuating oxidative stress in the liver. Most importantly, our finding strongly suggested that TREM-1/TLR4/NF- $\kappa B$ signaling pathway might play a vital role in the pathogenesis of acute liver injury, and its inhibition by MH could exert beneficial effects in the prevention of acute hepatic damage. 
A

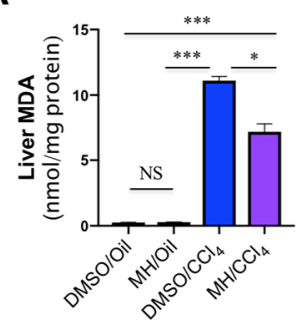

D

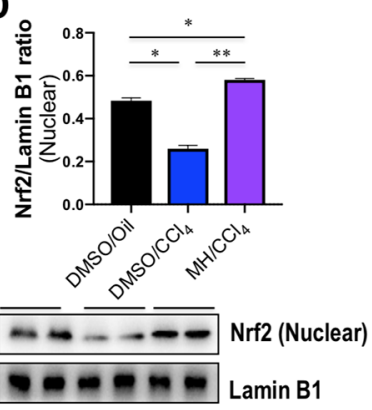

B

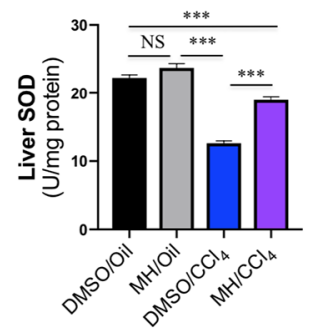

E

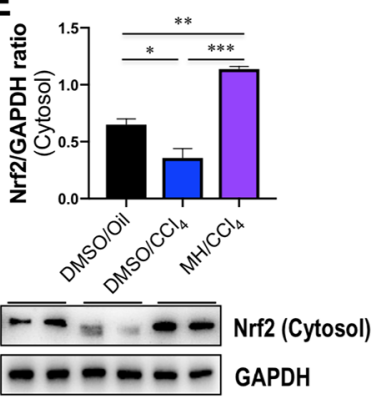

C

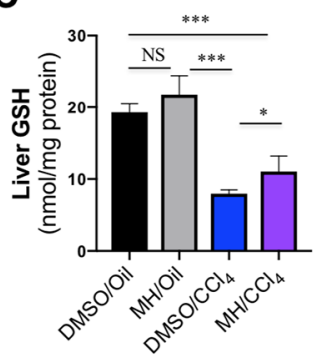

F

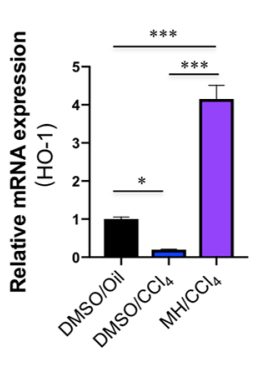

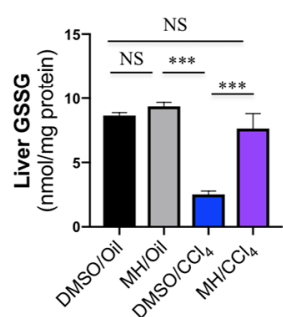

G

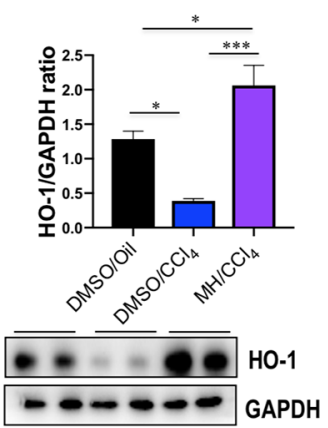

FIGURE 8 | Effect of morin hydrate (MH) on oxidative stress and nuclear factor erythroid 2-related factor 2 (Nrf2)/heme oxygenase-1 (HO-1) pathway in the liver of $\mathrm{CCl}_{4}$-treated mice. (A) Lipid peroxidation was assessed in terms of malondialdehyde (MDA) formation ( $n=6$ for each group). (B) Oxidative stress was assessed in terms of Cu/Zn SOD activity. Values are expressed as mean \pm SEM ( $n=6$ for each group). (C) Oxidative stress was assessed in terms of glutathione (GSH) and oxidized glutathione (GSSG). $n=6$ for each group. (D) Western blot analysis of Nrf2 protein in nuclear fractions of liver tissue; results normalized relative to expression of Lamin B1. (E) Western blot analysis of Nrf2 protein expression in cytosolic fractions of liver tissue; results normalized relative to expression of GAPDH. (F) Hepatic HO-1 mRNA expression was measured by quantitative reverse transcriptase-polymerase chain reaction (RT-PCR). Results are shown as fold change compared with DMSO/oil group and GAPDH served as loading control ( $n=5$ for each group). (G) Western blot analysis of HO-1 protein expression in the lysed liver tissue; results normalized relative to expression of $\mathrm{GAPDH}(n=3) .{ }^{\star} P<0.05,{ }^{\star \star} P<0.01,{ }^{\star \star \star} P<0.001$. NS indicates not significant.

A growing body of evidence indicates that natural products and their derivatives could prevent the deleterious effects of toxic agents by scavenging free radicals or modulating inflammatory response (Conner and Grisham, 1996; Lu et al., 2012; Singh et al., 2015; Hassan et al., 2017). Notably, MH, one of the most widely distributed flavonoids in plants, possesses strong free radical scavenging ability and potent hepatoprotective effects (Caselli et al., 2016; Lee et al., 2016; Naowaboot et al., 2016). Several studies in animal models have demonstrated that the administration of morin significantly prevented liver injury, inflammation, and fibrosis (Rizvi et al., 2015; Gu et al., 2017; Perumal et al., 2017; Tian et al., 2017; Li et al., 2018). For example, $\mathrm{MH}$ attenuated acetaminophen-induced liver injury by potentiating Nrf2 regulated survival mechanism (Rizvi et al., 2015). Wang et al. reported that morin reduced hepatic inflammation-associated lipid accumulation in high fructose-fed rats via inhibition of sphingosine kinase 1/sphingosine 1-phosphate signaling pathway (Wang et al., 2013). A recent study by Tian et al. demonstrated that $\mathrm{MH}$ could protect LPS/D-GalN-induced acute liver injury by activating Nrf2 signal pathways and inhibiting NF- $\kappa B$ activation (Tian et al., 2017). But the molecular mechanism of $\mathrm{MH}$ for hepatoprotective effects remains to be further clarified.

In the present study, we found that acute $\mathrm{CCl}_{4}$ intoxication induced hepatic injury, which was manifested in increased serum markers of liver damage, hepatocyte death, macrophage infiltration, and histopathological alterations (Figure 1). However, $\mathrm{MH}$ pretreatment reduced the levels of serum ALT and AST induced by $\mathrm{CCl}_{4}$ (Figure 1C) and preserved the structural integrity of the hepatocellular membrane (Figure 1D), which was further supported by the histopathological findings (Figure 1E).

It is now generally accepted that innate immune cells, that is, infiltrating monocytes/macrophages, Kupffer cells, and neutrophils, are activated after acute liver cell death (Antoniades et al., 2008). Indeed, our result demonstrated that infiltration of the liver macrophages significantly increased to $44.97 \pm 0.76$ cells per $\mathrm{HPF}$ at $24 \mathrm{~h}$ after $\mathrm{CCl}_{4}$ injection than in normal control animals $(12.83 \pm 1.04$ cells per $\mathrm{HPF})$. But $\mathrm{MH}$ pretreatment in $\mathrm{CCl}_{4^{-}}$ injected mice remarkably diminished macrophage infiltration into the liver as determined histologically by F4/80 staining (Figures 1F, G). Moreover, previous studies have confirmed that TREM-1 is an activating receptor that amplifies inflammatory response and is highly expressed in neutrophils and monocytes/ macrophages (Pelham and Agrawal, 2014; Tammaro et al., 2017; Tornai et al., 2019). Here, we found that TREM-1 was also involved in acute liver injury induced by $\mathrm{CCl}_{4}$ and that TREM-1 predominantly localized to sinusoidal regions in the liver (Figure 2A). In contrast, $24 \mathrm{~h}$ after $\mathrm{CCl}_{4}$ injection, the amount of TREM-1 was enhanced in the sinusoidal areas of injury livers (Figure 2A). However, pretreatment with $\mathrm{MH}$ inhibited TREM-1 expression in both gene and protein levels (Figure 2). Furthermore, in vitro LPS-stimulated RAW267.4 cells induced TREM-1 expression, while $\mathrm{MH}$ treatment significantly inhibited TREM-1 expression and the production of TNF- $\alpha$ and IL- $1 \beta$ (Figures 5A, B). Of note, this inhibitory effect $\mathrm{MH}$ on the expression of the TREM-1 in cell culture was further heightened after TREM-1 knockdown 
with siRNA (Figure 7). Our results and other recent reports have demonstrated that TREM-1 signaling contributes to proinflammatory pathway activation in liver injury, fibrosis, alcoholic liver disease, and NAFLD (Nguyen-Lefebvre et al., 2018; Rao et al., 2019; Tornai et al., 2019). Supporting our results, several studies in other organs have shown that TREM-1 blockade either by TREM-1-Fc or by a peptide attenuated the disease process (Klesney-Tait et al., 2006; Schenk et al., 2007; Pelham and Agrawal, 2014). Therefore, these data strongly suggested that TREM-1 may play a critical role in the pathogenesis of acute liver injury; and the hepatoprotective activity of $\mathrm{MH}$ was involved in the modulation of TREM-1 expression in macrophages.

Furthermore, it has been shown that TREM-1 can amplify TLR4-mediated as well as TLR2-mediated proinflammatory signaling (Ornatowska et al., 2007; Pelham and Agrawal, 2014; Tammaro et al., 2017). Particularly TLR4, which is mainly expressed on hepatic macrophages in the liver, contributes to liver injury, inflammation, and fibrosis (Mencin et al., 2009; Li et al., 2016a; Li et al., 2016b; Ding et al., 2018). In our current study, we found that pretreatment with $\mathrm{MH}$ of acute liver injury in mice decreased the levels of TLR4 mRNA and protein expression in livers (Figure 3); and this decrease may be the effect and mechanism of $\mathrm{MH}$ on amelioration of liver inflammation and necrosis. Consistent with our results, several in vivo and in vitro studies have also confirmed that morin effectively downregulated the expression of TLR4 (Heeba and Mahmoud, 2014; Tian et al., 2017). Additionally, blockade or silencing of TREM-1 can inhibit TLR4-mediated induction of cytokines upon LPS activation (Pelham and Agrawal, 2014; Tornai et al., 2019).

Our study has also shown that $\mathrm{MH}$ pretreatment potently inhibited I $\kappa \mathrm{B} a$ degradation and subsequent NF- $\mathrm{B}$ p 65 nuclear translocation in liver of $\mathrm{aCl}_{4}$-induced animal model as compared with vehicle pretreatment of mice (Figures $4 \mathbf{A}-\mathbf{C}$ ). Additionally, $\mathrm{MH}$ exerted an inhibitory effect on NF- $\kappa \mathrm{B}$ activation and further reduced the expression of its downstream inflammatory cytokines, such as TNF- $\alpha$, IL-1 $\beta$, and IL-6 (Figure 4D). In this in vitro study, we also demonstrated that $\mathrm{MH}$ prevents the release of proinflammatory cytokines in LPS-stimulated macrophages by inhibiting TREM-1/ TLR4/NF- $\kappa B$ signaling pathway (Figure 6). Similarly, it has been shown that $\mathrm{MH}$ suppresses the activation of NF- $\mathrm{BB}$ and downstream proinflammatory mediators in various experimental models (Wang et al., 2013; Tian et al., 2017; Sharma et al., 2018).

On the other hand, pretreatment with $\mathrm{MH}$ also obviously decreased hepatic MDA content and enhanced hepatic GSH and SOD activities that were altered by injection of a single dose of $\mathrm{CCl}_{4}$ (Figures 8A-C). GSH is a particularly efficient intracellular antioxidant that maintains intracellular redox status (McGregor and Lang, 1996), and SOD is an endogenous enzymatic antioxidant that plays synergistic actions in scavenging of free radicals by transforming them to less deleterious molecules (McGregor and Lang, 1996). Furthermore, Nrf2 is a redox-regulated transcription factor involved in the modulation of antioxidant defense systems (Anuranjani and Bala, 2014). We found that the mice receiving $\mathrm{CCl}_{4}$ alone have a remarkable decrease in Nrf2 protein levels in both nuclear and cytoplasm, which was reversed by $\mathrm{MH}$ (Figures $8 \mathrm{D}, \mathrm{E})$, suggesting that $\mathrm{MH}$ pretreatment to $\mathrm{CCl}_{4}$-induced mice significantly enhanced nuclear translocation of Nrf2 (Tian et al.,
2017). Also, $\mathrm{MH}$ induced the expression of Nrf2's downstream target HO-1 expression in both mRNA and protein (Figures $\mathbf{8 F}$, G), therefore leading to enhanced antioxidative defense in the liver.

Additionally, previous studies have revealed that oxidative stress can promote inflammation by increasing NF- $\kappa$ B activation (Shi et al., 2003; Nery-Flores et al., 2018; Sharma et al., 2018) and that Nrf2 can negatively regulate the NF- $\kappa \mathrm{B}$ signaling and can inhibit its downstream proinflammatory response and oxidative injury in mice (Shi et al., 2003; Lee et al., 2014; Wardyn et al., 2015). Thus, the inhibition of NF- $\mathrm{BB}$ signaling observed in the liver may be due to, in part at least, the antioxidative potency of $\mathrm{MH}$.

\section{CONCLUSIONS}

In summary, our current in vitro and in vivo study demonstrated the protective effects of $\mathrm{MH}$ on acute liver injury and provided a deep understanding of the molecular mechanisms of $\mathrm{MH}$ for hepatoprotective activity in the following ways: (i) blocking the TREM-1-mediated inflammatory response in macrophages and (ii) attenuating extensive oxidative stress through modulation of the Nrf2/HO-1 pathway in the liver. This multiple-target approach provided a potential therapeutic option to protect against liver injury.

\section{DATA AVAILABILITY}

The raw data supporting the conclusions of this manuscript will be made available by the authors, without undue reservation, to any qualified researcher.

\section{ETHICS STATEMENT}

The animal study was reviewed and approved by the Animal Care Committee of Zhongshan Hospital and the study was performed in accordance with the Guiding Principles for the Care and Use of Laboratory Animals approved by the Fudan University Animal Care Committee.

\section{AUTHOR CONTRIBUTIONS}

$\mathrm{XL}$ and CT conceived the study and wrote the manuscript; XL, $\mathrm{QY}$, and CT contributed to the work designing, performing, analyzing, and interpreting data from all the experiments; QY, $\mathrm{JH}, \mathrm{QJ}$, and XL participated in the design, acquisition, analysis, and interpretation of data; CT, BX, FC, and XL carried out the animal model and all the in vivo animal experiments; CT and XL interpreted the data and finalized the article. All authors have critically revised and approved the final manuscript and agreed to be accountable for all aspects of the work.

\section{FUNDING}

This work was supported by the National Natural Science Foundation of China (grant number: 81170398) and Shanghai Natural Science Foundation (grant number: 18ZR1406600). 


\section{REFERENCES}

Antoniades, C. G., Berry, P. A., Wendon, J. A., and Vergani, D. (2008). The importance of immune dysfunction in determining outcome in acute liver failure. J. Hepatol. 49, 845-861. doi: 10.1016/j.jhep.2008.08.009

Anuranjani, and Bala, M. (2014). Concerted action of Nrf2-ARE pathway, MRN complex, HMGB1 and inflammatory cytokines-implication in modification of radiation damage. Redox Biol. 2, 832-846. doi: 10.1016/j.redox.2014.02.008

Bataille, A. M., and Manautou, J. E. (2012). Nrf2: a potential target for new therapeutics in liver disease. Clin. Pharmacol. Ther. 92, 340-348. doi: 10.1038/clpt.2012.110

Bernal, W., Auzinger, G., Dhawan, A., and Wendon, J. (2010). Acute liver failure. Lancet 376, 190-201. doi: 10.1016/S0140-6736(10)60274-7

Caselli, A., Cirri, P., Santi, A., and Paoli, P. (2016). Morin: a promising natural drug. Curr. Med. Chem. 23, 774-791. doi: 10.2174/0929867323666160106150821

Conner, E. M., and Grisham, M. B. (1996). Inflammation, free radicals, and antioxidants. Nutrition 12, 274-277. doi: 10.1016/S0899-9007(96)00000-8

Ding, Y., Liu, P., Chen, Z. L., Zhang, S. J., Wang, Y. Q., Cai, X., et al. (2018). Emodin attenuates lipopolysaccharide-induced acute liver injury via inhibiting the TLR4 signaling pathway in vitro and in vivo. Front. Pharmacol. 9, 962. doi: 10.3389/fphar.2018.00962

Dong, D., Yin, L., Qi, Y., Xu, L., and Peng, J. (2015). Protective effect of the total saponins from Rosa laevigata Michx fruit against carbon tetrachloride-induced liver fibrosis in rats. Nutrients 7, 4829-4850. doi: 10.3390/nu7064829

Gu, M., Zhang, Y., Liu, C., Wang, D., Feng, L., Fan, S., et al. (2017). Morin, a novel liver $\mathrm{X}$ receptor alpha/beta dual antagonist, has potent therapeutic efficacy for nonalcoholic fatty liver diseases. Br. J. Pharmacol. 174, 30323044. doi: 10.1111/bph.13933

Hassan, H. M., Guo, H., Yousef, B. A., Ping-Ping, D., Zhang, L., and Jiang, Z. (2017). Dexamethasone pretreatment alleviates isoniazid/lipopolysaccharide hepatotoxicity: inhibition of inflammatory and oxidative stress. Front. Pharmacol. 8, 133. doi: 10.3389/fphar.2017.00133

He, Z., Li, X., Chen, H., He, K., Liu, Y., Gong, J., et al. (2016). Nobiletin attenuates lipopolysaccharide/D-galactosamine induced liver injury in mice by activating the Nrf2 antioxidant pathway and subsequently inhibiting NFkappaB mediated cytokine production. Mol. Med. Rep. 14, 5595-5600. doi: 10.3892/ mmr.2016.5943

Heeba, G. H., and Mahmoud, M. E. (2014). Therapeutic potential of morin against liver fibrosis in rats: modulation of oxidative stress, cytokine production and nuclear factor kappa B. Environ. Toxicol. Pharmacol. 37, 662-671. doi: 10.1016/j.etap.2014.01.026

Horrillo, R., Planaguma, A., Gonzalez-Periz, A., Ferre, N., Titos, E., Miquel, R., et al. (2007). Comparative protection against liver inflammation and fibrosis by a selective cyclooxygenase- 2 inhibitor and a nonredox-type 5-lipoxygenase inhibitor. J. Pharmacol. Exp. Ther. 323, 778-786. doi: 10.1124/jpet.107.128264

Klesney-Tait, J., Turnbull, I. R., and Colonna, M. (2006). The TREM receptor family and signal integration. Nat. Immunol. 7, 1266-1273. doi: 10.1038/ ni1411

Krenkel, O., and Tacke, F. (2017). Liver macrophages in tissue homeostasis and disease. Nat. Rev. Immunol. 17, 306-321. doi: 10.1038/nri.2017.11

Kubes, P., and Mehal, W. Z. (2012). Sterile inflammation in the liver. Gastroenterology 143, 1158-1172. doi: 10.1053/j.gastro.2012.09.008

Lee, I. C., Kim, S. H., Baek, H. S., Moon, C., Kang, S. S., Kim, S. H., et al. (2014). The involvement of Nrf2 in the protective effects of diallyl disulfide on carbon tetrachloride-induced hepatic oxidative damage and inflammatory response in rats. Food Chem. Toxicol. 63, 174-185. doi: 10.1016/j.fct.2013.11.006

Lee, K. M., Lee, Y., Chun, H. J., Kim, A. H., Kim, J. Y., Lee, J. Y., et al. (2016). Neuroprotective and anti-inflammatory effects of morin in a murine model of Parkinson's disease. J. Neurosci. Res. 94, 865-878. doi: 10.1002/jnr.23764

Li, X., Jin, Q., Yao, Q., Xu, B., Li, L., Zhang, S., et al. (2018). The flavonoid quercetin ameliorates liver inflammation and fibrosis by regulating hepatic macrophages activation and polarization in mice. Front Pharmacol. 9, 72. doi: 10.3389/ fphar.2018.00072

Li, X., Jin, Q., Yao, Q., Xu, B., Li, Z., and Tu, C. (2016a). Quercetin attenuates the activation of hepatic stellate cells and liver fibrosis in mice through modulation of HMGB1-TLR2/4-NF-kappaB signaling pathways. Toxicol. Lett. 261, 1-12. doi: 10.1016/j.toxlet.2016.09.002

Li, X., Liu, H. C., Yao, Q. Y., Xu, B. L., Zhang, S. C., and Tu, C. T. (2016b). Quercetin protects mice from ConA-induced hepatitis by inhibiting
HMGB1-TLR expression and down-regulating the nuclear factor kappa B pathway. Inflammation 39, 96-106. doi: 10.1007/s10753-015-0227-9

Lin, D., Sun, Z., Jin, Z., Lei, L., Liu, Y., Hu, B., et al. (2018). Matrix remodeling associated 7 deficiency alleviates carbon tetrachloride-induced acute liver injury in mice. Front Immunol. 9, 773. doi: 10.3389/fimmu.2018.00773

Liu, H., Dinkova-Kostova, A. T., and Talalay, P. (2008). Coordinate regulation of enzyme markers for inflammation and for protection against oxidants and electrophiles. Proc. Natl. Acad. Sci. U. S. A. 105, 15926-15931. doi: 10.1073/ pnas.0808346105

Lu, B., Xu, Y., Xu, L., Cong, X., Yin, L., Li, H., et al. (2012). Mechanism investigation of dioscin against $\mathrm{CCl}_{4}$-induced acute liver damage in mice. Environ. Toxicol. Pharmacol. 34, 127-135. doi: 10.1016/j.etap.2012.03.010

MadanKumar, P., NaveenKumar, P., Manikandan, S., Devaraj, H., and NiranjaliDevaraj, S. (2014). Morin ameliorates chemically induced liver fibrosis in vivo and inhibits stellate cell proliferation in vitro by suppressing Wnt/beta-catenin signaling. Toxicol. Appl. Pharmacol. 277, 210-220. doi: 10.1016/j.taap.2014.03.008

Malhi, H., and Gores, G. J. (2008). Cellular and molecular mechanisms of liver injury. Gastroenterology 134, 1641-1654. doi: 10.1053/j.gastro.2008.03.002

McGregor, D., and Lang, M. (1996). Carbon tetrachloride: genetic effects and other modes of action. Mutat. Res. 366, 181-195. doi: 10.1016/ S0165-1110(96)90027-5

Mencin, A., Kluwe, J., and Schwabe, R. F. (2009). Toll-like receptors as targets in chronic liver diseases. Gut 58, 704-720. doi: 10.1136/gut.2008.156307

Mortezaee, K., and Khanlarkhani, N. (2018). Melatonin application in targeting oxidative-induced liver injuries: a review. J. Cell. Physiol. 233, 4015-4032. doi: 10.1002/jcp.26209

Naowaboot, J., Wannasiri, S., and Pannangpetch, P. (2016). Morin attenuates hepatic insulin resistance in high-fat-diet-induced obese mice. J. Physiol. Biochem. 72, 269-280. doi: 10.1007/s13105-016-0477-5

Nery-Flores, S. D., Mendoza-Magana, M. L., Ramirez-Herrera, M. A., RamirezVazquez, J. J., Romero-Prado, M., Cortez-Alvarez, C. R., et al. (2018). Curcumin exerted neuroprotection against ozone-induced oxidative damage and decreased NF-kappaB activation in rat hippocampus and serum levels of inflammatory cytokines. Oxid. Med. Cell. Longev. 2018, 9620684. doi: $10.1155 / 2018 / 9620684$

Nguyen-Lefebvre, A. T., Ajith, A., Portik-Dobos, V., Horuzsko, D. D., Arbab, A. S., Dzutsev, A., et al. (2018). The innate immune receptor TREM-1 promotes liver injury and fibrosis. J. Clin. Invest. 128, 4870-4883. doi: 10.1172/JCI98156

Ornatowska, M., Azim, A. C., Wang, X., Christman, J. W., Xiao, L., Joo, M., et al. (2007). Functional genomics of silencing TREM-1 on TLR4 signaling in macrophages. Am. J. Physiol Lung Cell Mol. Physiol. 293, L1377-L1384. doi: 10.1152/ajplung.00140.2007

Pelham, C. J., and Agrawal, D. K. (2014). Emerging roles for triggering receptor expressed on myeloid cells receptor family signaling in inflammatory diseases. Expert Rev. Clin. Immunol. 10, 243-256. doi: 10.1586/1744666X.2014.866519

Perumal, N., Perumal, M., Halagowder, D., and Sivasithamparam, N. (2017). Morin attenuates diethylnitrosamine-induced rat liver fibrosis and hepatic stellate cell activation by co-ordinated regulation of Hippo/Yap and TGFbetal/Smad signaling. Biochimie 140, 10-19. doi: 10.1016/j.biochi.2017.05.017

Rao, S., Huang, J., Shen, Z., Xiang, C., Zhang, M., and Lu, X. (2019). Inhibition of TREM-1 attenuates inflammation and lipid accumulation in diet-induced nonalcoholic fatty liver disease. J. Cell. Biochem. 120 (7), 11867-11877. doi: $10.1002 /$ jcb. 28468

Reilkoff, R. A., Bucala, R., and Herzog, E. L. (2011). Fibrocytes: emerging effector cells in chronic inflammation. Nat. Rev. Immunol. 11, 427-435. doi: 10.1038/nri2990

Rizvi, F., Mathur, A., and Kakkar, P. (2015). Morin mitigates acetaminopheninduced liver injury by potentiating Nrf2 regulated survival mechanism through molecular intervention in PHLPP2-Akt-Gsk3beta axis. Apoptosis 20, 1296-1306. doi: 10.1007/s10495-015-1160-y

Schenk, M., Bouchon, A., Seibold, F., and Mueller, C. (2007). TREM-1expressing intestinal macrophages crucially amplify chronic inflammation in experimental colitis and inflammatory bowel diseases. J. Clin. Invest. 117, 3097-3106. doi: 10.1172/JCI30602

Seki, E., De Minicis, S., Osterreicher, C. H., Kluwe, J., Osawa, Y., Brenner, D. A., et al. (2007). TLR4 enhances TGF-beta signaling and hepatic fibrosis. Nat. Med. 13, 1324-1332. doi: 10.1038/nm1663

Sharma, S. H., Kumar, J. S., Chellappan, D. R., and Nagarajan, S. (2018). Molecular chemoprevention by morin-a plant flavonoid that targets nuclear factor 
kappa B in experimental colon cancer. Biomed. Pharmacother. 100, 367-373. doi: 10.1016/j.biopha.2018.02.035

Shi, X. Z., Lindholm, P. F., and Sarna, S. K. (2003). NF-kappa B activation by oxidative stress and inflammation suppresses contractility in colonic circular smooth muscle cells. Gastroenterology 124, 1369-1380. doi: 10.1016/ S0016-5085(03)00263-4

Sims, G. P., Rowe, D. C., Rietdijk, S. T., Herbst, R., and Coyle, A. J. (2010). HMGB1 and RAGE in inflammation and cancer. Annu. Rev. Immunol. 28, 367-388. doi: 10.1146/annurev.immunol.021908.132603

Singh, D., Cho, W. C., and Upadhyay, G. (2015). Drug-induced liver toxicity and prevention by herbal antioxidants: an overview. Front. Physiol. 6, 363. doi: 10.3389/fphys.2015.00363

Tammaro, A., Derive, M., Gibot, S., Leemans, J. C., Florquin, S., and Dessing, M. C. (2017). TREM-1 and its potential ligands in non-infectious diseases: from biology to clinical perspectives. Pharmacol. Ther. 177, 81-95. doi: 10.1016/j. pharmthera.2017.02.043

Tian, Y., Li, Z., Shen, B., Zhang, Q., and Feng, H. (2017). Protective effects of morin on lipopolysaccharide/d-galactosamine-induced acute liver injury by inhibiting TLR4/NF-kappaB and activating Nrf2/HO-1 signaling pathways. Int. Immunopharmacol. 45, 148-155. doi: 10.1016/j.intimp.2017.02.010

Tornai, D., Furi, I., Shen, Z. T., Sigalov, A. B., Coban, S., and Szabo, G. (2019). Inhibition of triggering receptor expressed on myeloid cells 1 ameliorates inflammation and macrophage and neutrophil activation in alcoholic liver disease in mice. Hepatol. Commun. 3, 99-115. doi: 10.1002/hep4.1269
Wang, X., Zhang, D. M., Gu, T. T., Ding, X. Q., Fan, C. Y., Zhu, Q., et al. (2013). Morin reduces hepatic inflammation-associated lipid accumulation in high fructose-fed rats via inhibiting sphingosine kinase 1/sphingosine 1-phosphate signaling pathway. Biochem. Pharmacol. 86, 1791-1804. doi: 10.1016/j. bcp.2013.10.005

Wardyn, J. D., Ponsford, A. H., and Sanderson, C. M. (2015). Dissecting molecular cross-talk between Nrf2 and NF-kappaB response pathways. Biochem. Soc. Trans. 43, 621-626. doi: 10.1042/BST20150014

Zhang, X., Xu, L., Yin, L., Qi, Y., Xu, Y., Han, X., et al. (2015). Quantitative chemical proteomics for investigating the biomarkers of dioscin against liver fibrosis caused by $\mathrm{CCl}_{4}$ in rats. Chem. Commun. (Camb) 51, 11064-11067. doi: 10.1039/C4CC09160D

Conflict of Interest Statement: The authors declare that the research was conducted in the absence of any commercial or financial relationships that could be construed as a potential conflict of interest.

Copyright $\odot 2019 \mathrm{Li}$, Yao, Huang, Jin, Xu, Chen and Tu. This is an open-access article distributed under the terms of the Creative Commons Attribution License (CC BY). The use, distribution or reproduction in other forums is permitted, provided the original author(s) and the copyright owner(s) are credited and that the original publication in this journal is cited, in accordance with accepted academic practice. No use, distribution or reproduction is permitted which does not comply with these terms. 